\title{
Wave-current interactions in a tide dominated estuary
}

Bolaños, R. *

National Oceanography Centre

Now at:

DHI

Agern Alle 5

Hørsholm, 2970, Denmark

Phone: +4545169580

Fax: +45 45169292

Email: rbol@dhigroup.com

Brown, J.M.

National Oceanography Centre Joseph Proudman Building 6 Brownlow Street, Liverpool, L3 5DA, UK.

Phone: +44 (0) 1517954971

Fax: +44 (0) 1517954801

Email: jebro@noc.ac.uk

Souza, A.J.

National Oceanography Centre

Joseph Proudman Building 6 Brownlow Street, Liverpool, L3 5DA, UK.

Phone: +44 (0) 1517954820

Fax: +44 (0) 1517954801

Email: ajso@noc.ac.uk

* Corresponding author 


\section{Abstract}

There is a need to understand the interactions of waves and currents in the nearshore and estuarine areas. By using observational data and an advanced model an assessment of the wavecurrent interactions was performed in a hypertidal estuary. The circulation model includes both barotropic and baroclinic processes arising from tides, rivers and atmospheric forcing. It is coupled to a spectral wave model and a turbulence model. Waves within the estuary are strongly modulated by the tide. Significant wave height and period are mainly controlled by time-varying water depth, but wave periods are also affected by a Doppler shift produced by the current. The major-axis depth-averaged current component is tidally dominated and wave induced processes do not have a significant effect on it. However, the inclusion of wave effects, in particular 3D radiation stress, improves the depth-averaged minor-axis (transverse) current component. The residual currents show a clear two-layer system, indicating that the baroclinic river influence is the dominant process. The wave effects are second order, but their consideration improves the long-term modelled residual circulation profile, specially the along estuary component. The main improvement appears when a 3-dimensional radiation stress coupling is considered. The 3D version of radiation stress produced better results than the $2 \mathrm{D}$ version. Within the estuary, wave setup has little effect on the storm surge, while 2-way wave-current interaction improved the wave simulation. Using a 3D Doppler shift further improved the model compared with using a $2 \mathrm{D}$ version.

Keywords: Estuarine dynamics, coastal modelling, wave-current interaction, POLCOMS, WAM, Dee estuary, wave storm impact 


\section{Introduction}

Coastal waves and currents are highly variable and can have a significant impact on human activities and structures (Wolf et al., 2011). There is also a need to understand the interactions of waves and currents in the near-shore zone as nonlinear effects become more important. Waves can contribute to the circulation, which then modifies the waves creating a wave-current feedback mechanism. The impact of currents, waves and surges at the coast are closely linked (Brown et al., 2011; Jones and Davies, 1998) and thus the prediction of wind-waves and ocean currents is of great importance for the management (including navigation) of coastal areas.

There have been a number of research studies dealing with such interactions e.g. wind - waves (Chen et al., 2013; Donelan et al., 2012; Fan et al., 2012; Janssen, 1989; Makin and Kudryavtsev, 1999, 2002) where the effects of waves on the wind boundary layer are studied. For a comprehensive review the reader is referred to a special issue in Journal of Geophysical Research (see Babanin et al., 2012). Wave-current interactions have also been subject of several theoretical and practical studies (Ardhuin et al., 2008b; Jorda et al., 2007; Kumar et al., 2012; Mellor, 2003, 2005; Michaud et al., 2012). Andrews and McIntyre (1978a) have derived an exact theory for the interaction of waves with a Lagrangian mean flow including the wave momentum into the mean flow evolution. Mellor $(2003,2005,2008)$ derived, in an Eulerian framework, a set of equations to be used in ocean models based on linear wave theory, assuming a flat bottom. Sheng and Liu (2011) show Mellor's (later 2008) method is more accurate, than alternative 3D methods, at hindcasting wave-induced circulation. Mellor's formulations have been subject of debate regarding some inconsistencies in the derivations (Ardhuin et al., 2008a; Bennis et al., 
2011) and at the same time other approaches have been developed. Ardhuin et al. (2008b), following Andrews and McIntyre (1978a, 1978b), derived explicit wave-averaged primitive equations limited to 2nd order wave theory. McWilliams et al. (2004) derive a set of equations for use in finite water depth which led to a Vortex force representation evaluated by e.g. Lane et al. (2007) and implemented in the ROMS-SWAN model (Kumar et al., 2012; Uchiyama et al., 2010). The main effects of waves on the mean flow commonly considered are due to radiation stress and Stokes drift, although interaction with turbulence and bottom stress can also be important (Babanin et al., 2009; Rascle and Ardhuin, 2009; Rascle et al., 2006). Several numerical, experimental and observational investigations have been done to understand wave processes in upper ocean dynamics. Ardhuin et al. (2009) used radar measurements to estimate Stokes drift showing that typically it is between $0.6 \%$ and $1.3 \%$ of the wind speed (the direct wind induced current is about $1-1.8 \%$ the wind speed). Weber et al. (2006) showed that the Eulerian and Lagrangian approaches for the fluid motion produce the same mean wave induced flux in the surface layer: for their simulations the wave induced stress constituted about $50 \%$ of the total atmospheric stress for moderate to strong winds. Coupled 2D current-wave models have shown the importance of considering wave effects when modelling water levels due to a hurricane in the Gulf of Mexico and a storm in the Adriatic Sea (Roland et al., 2009), and for storm surges in the Irish Sea (Brown et al., 2011; Brown and Wolf, 2009). Osuna and Wolf (2005) and Wolf et al. (2002) studied the effects of waves on the hydrodynamics of the Irish Sea, further work by Brown et al. (2013b) studied the effects of 2D radiation stress formulation on a 3D hydrodynamic model showing the benefit of including these processes without compromising computational time. Tang et al. (2007) implemented wave-current interaction in a 3D ocean model (POM) and a spectral wave model (WAVEWATCH III) following Jenkins 
(1987) and evaluated the model by comparison with surface drifters. They showed that Stokes drift is a dominant effect for surface drift speed with a contribution of about $35 \%$. They also showed a reduction of momentum transfer from wind to currents if waves are taken into account. Wave-current interaction has also been studied in a flume, observing unexpected changes in the mean horizontal wave profile (Groeneweg and Battjes, 2003) and wave induced mixing (Babanin, 2006).

Wave-current interactions in estuaries and coastal lagoons have been relatively less studied. Some examples are Bender and Wong (1993), Lin and Perrie (2003), Piedracoba et al. (2005) and Pleskachevsky et al. (2009) who show the importance of modelling depth and velocity variations when simulating waves in estuaries. Internal estuarine wave effects can be time limited, due to the presence of dissipative banks at the mouth. Often in wave influenced estuaries the wave related processes are greater during high water elevations when wave dissipation over the banks at the mouth is least. The timing of the wave conditions relative to the tidal flow at the estuary mouth can also be important for sediment dynamics.

Bolaños et al. (2013) modelled the Dee estuary during calm weather conditions, showing the effect of wind and river on stratification and residual circulation. Although the Dee is hypertidal with a very small river contribution, it was shown that baroclinicity can still dominate the residual circulation. However, the effect of more energetic atmospheric conditions and wave effects were not studied. The main objectives of the present work are therefore to evaluate the main wave-current interaction processes in the, hypertidal, Dee estuary using observations and an advanced 3-dimensional (3D) wave-current-turbulence model. Investigations under similar 
conditions are limited and thus the paper brings new insight into the importance of these processes. A comprehensive model-observation comparison for waves, currents and surge is performed to fully assess the skill of the modelling system at simulating pertinent processes. In the next section the Dee estuary is described. Section 3 details the Proudman Oceanographic Laboratory Ocean Modelling System (POLCOMS) and its application to the Dee estuary. Section 4 presents the data available and describes the environmental conditions. Section 5 discusses the results, and the final concluding remarks are given in Section 6.

\section{The Dee estuary}

The Dee is a funnel-shaped hypertidal estuary situated in the eastern Irish Sea (Figure 1). It has a length of about $30 \mathrm{~km}$, with a maximum width of $8.5 \mathrm{~km}$ at the estuary mouth. The average tidal prism is $4 \times 10^{8} \mathrm{~m}^{3}$ and the annual mean river discharge is only $31 \mathrm{~m}^{3} \mathrm{~s}^{-1}$ making the Dee a tidally dominated estuary. The tidal range during mean spring at Hilbre Island is of the order of $10 \mathrm{~m}$. The main channel bifurcates $12 \mathrm{~km}$ seaward from the canalized river at the head of the estuary, resulting in two (more than $20 \mathrm{~m}$ ) deep channels extending into Liverpool Bay, the Hilbre channel is on the east and the Welsh channel is on the west. The two shorelines of the estuary show a marked contrast between the industrialized usage of the coastal belt in Wales (west coast) and residential and recreational usage in England (east coast). The estuary has been subject of several man made modifications such as canalizations and training walls causing siltation and accretion on the eastern shore and colonization of areas by saltmarsh. The estuary contains extensive areas of intertidal sand and mudflats (Hutchinson, 1994; Hutchinson and Prandle, 1994), which support a benthic fauna. Large areas of saltmarsh also occur at its head and along

part of the east shore. The three sandstone islands which comprise the Hilbre Island complex and 
Red Rocks at the northeast tip of the Wirral peninsula represent the only natural hard rock coast within the estuary.

\section{The numerical model}

\subsection{POLCOMS}

POLCOMS is a 3D numerical model formulated in a spherical polar, terrain following coordinate system (sigma coordinates), on a B-Grid (Holt and James, 2001). It solves the incompressible, hydrostatic, Boussinesq equation of motion separated into depth varying and depth independent parts to allow time splitting between depth-independent $(\overline{\boldsymbol{u}})$ and depthdependent $\left(\boldsymbol{u}_{r}\right)$ components. The eastward velocity is then $u=\bar{u}+u_{r}$ and the northward component is $v=\bar{v}+v_{r}$. For the turbulence, POLCOMS is coupled with the Global Ocean Turbulence Model (GOTM, Umlauf et al., 2005). This allows for more sophisticated turbulence modelling, such as accounting for turbulent mixing with TKE injection at the surface to represent white-capping of waves. A study of turbulence modelling using POLCOMS in the Northwest European continental shelf (Holt and Umlauf, 2008) has shown the $\kappa-\varepsilon$ formulation to better represent mixing fronts, thus it has been applied again here. Another process considered in the model is wetting and drying. For wave processes, POLCOMS is coupled with the spectral wave model WAM (Monbaliu et al., 2000). For 2D wave-current interaction (see Table 1), wave refraction and Doppler shift are included using the depth-averaged current; the bottom friction is enhanced by waves (Mellor, 2002), while a JONSWAP bottom friction is applied in WAM after it was found to perform better in the Dee estuary (Brown, 2010); the wind drag is modified by the presence of the wave field using a wave dependent Charnock parameter (Brown and Wolf, 2009). To ensure numerical stability WAM limits the growth of the high frequency end of the 
wave spectrum (Monbaliu et al., 2000). However, nearshore, the default limit restricts the rate of change of the wave spectrum, preventing tidal modulation of the waves. An improved wave prediction in shallow water is obtained by relaxing this limit (Brown, 2010). For 3D wavecurrent interaction the model uses Mellor (2003, 2005), implemented and tested by Bolaños et al. (2009), Bolaños et al. (2011) and Brown et al. (2011). Stokes' drift is estimated by an integration of the wave spectra in the form:

$$
U_{S \propto}(\sigma)=2 g \int_{\theta} \int_{f} \frac{k_{\alpha}}{c} \frac{\cosh 2 k D(1+\sigma)}{\sinh 2 D K D} F d f d \theta
$$

where $\alpha$ refers to the $x$ or $y$ component of the Stokes velocity vector $U_{S \alpha}$ (and of the wave number vector $k$ ), $c$ is the respective wave celerity, $D$ water depth, $F(f, \theta)$ the wave energy spectrum, $g$ acceleration due to gravity, $\theta$ and $f$ are the direction and frequency of each spectral component, $\sigma$ is the sigma coordinate.

The Doppler velocity $\left(u_{A \alpha}\right)$ that modifies the wave dispersion relation is evaluated according to the expression based on Kirby and Chen, (1989) analysed and described by Mellor (2003), and it is defined as:

$$
u_{A \propto}(\sigma)=2 \int_{-1}^{0} u \frac{k D \cosh 2 k D(1+\sigma)}{\sinh 2 K D} d \sigma
$$

where $u$ represents the total (depth-averaged and depth-varying) velocity. 
Longuet-Higgins and Stewart $(1962,1964)$ described the radiation stress of surface waves as an excess flux of momentum by the waves. Therefore the momentum conservation modifies the current field by changes of the radiation stress. Its effects are more evident in shallow water due to wave energy gradients. Mellor (2003) developed a formulation to explicitly take into account this process in ocean models. The expressions of Mellor were given for a monochromatic wave but they can be adapted so that a wave spectrum can be accounted for:

$$
\begin{gathered}
S_{\alpha \beta}(\sigma)=\int_{\theta} \int_{f} k D\left[\frac{k_{\alpha} k_{\beta}}{k^{2}} F_{C S} F_{C C}+\delta_{\alpha \beta}\left(F_{C S} F_{C C}-F_{S S} F_{C S}\right)\right] F d f d \theta \\
S_{p \beta}(\sigma)=\int_{\theta} \int_{f} k D\left[\frac{F_{S S} \partial F}{2 \partial x_{\alpha}}+\left\{(1+\sigma) F_{C S}-\frac{\cosh k D}{\sinh k D} F_{S S}\right\} F \frac{\partial k D}{d x_{\alpha}}\right]\left(F_{C C}+F_{S S}\right) d f d \theta
\end{gathered}
$$

Where $\alpha, \beta$ are the horizontal components, $\delta_{\alpha \beta}=1$ for $\alpha=\beta$ and the depth dependent functions are defined as:

$$
\begin{aligned}
& F_{S S}=\frac{\sinh k D(1+\sigma)}{\sinh k D} ; \quad F_{C S}=\frac{\cosh k D(1+\sigma)}{\sinh k D} \\
& F_{S C}=\frac{\sinh k D(1+\sigma)}{\cosh k D} ; \quad F_{C C}=\frac{\cosh k D(1+\sigma)}{\cosh k D}
\end{aligned}
$$

A 2D version of radiation stress following Longuet-Higgins and Stewart (1964) and Mastenbroek et al. (1993) is also available (e.g. Brown et al., 2013b) and is included in the present analysis. This method applies a vertically uniform stress to the depth-independent velocity component within the POLCOMS, whereas the 3D method applies a vertically-varying stress to the depth-varying velocity component within POLCOMS. 


\subsection{Model set-up}

To model wave-current-turbulence processes in the Dee estuary within Liverpool Bay, the POLCOMS-WAM-GOTM modelling system (Brown et al., 2010; Bolaños et al., 2013) has been used considering 3D wave-current interaction. Accounting for freshwater input, surface heating and the offshore temperature and salinity structure enables a baroclinic-wave-tide-surge model to be set-up.

To capture the (waves, surge, temperature and salinity) conditions around the offshore boundary to Liverpool Bay a system of nested model grids was used. The Liverpool Bay model ( 180 m horizontal resolution and 10 sigma layers) was forced with boundary conditions from the Irish Sea model ( 1.8 km resolution) (Bolaños et al., 2013; Brown et al., 2011). Fields generated by the UK Met Office Northwest European Continental Shelf (mesoscale) model were used to force the atmospheric conditions. These data consisted of hourly wind velocity at $10 \mathrm{~m}$ and atmospheric pressure, as well as air temperature, relative humidity and cloud cover every three hours, with a resolution of $\sim 12 \mathrm{~km}$. It has been previously shown (Bolaños et al., 2013) that even in a hypertidal estuary, weak river inflow can significantly impact the residual estuarine circulation. Freshwater at the river sources within the POLCOMS model domains was accounted for using daily averaged river discharges from available river gauging stations across the study area from the Centre of Ecology and Hydrology (CEH). The Liverpool Bay model was initialized with a salinity of $35 \mathrm{PSU}$ and a temperature of $7{ }^{\circ} \mathrm{C}$. A one month spin-up period was then used to generate the baroclinic conditions before the simulations were performed. The wave model was spun up over 1 day prior to the study period and had a $3 \mathrm{~s}$ propagation time step with 
a $12 \mathrm{~s}$ source term time step. Information exchange between POLCOMS and WAM occurred at the same rate as the baroclinic computation, every $9 \mathrm{~s}$. The directional wave spectra were discretized in 25 frequencies and 24 directions.

Table 1 summarizes the Dee model simulations used to investigate wave-current processes in the study area. All the runs included the same boundary conditions from the Irish Sea model and wetting and drying, but different forcing were considered to investigate the local 3D water structure and the effect of wave-current interaction. The reference run (P-ref) included atmospheric forcing (wind, pressure and heat transfer) and baroclinicity induced by river inputs. In the run Pnostrat the river input was removed to assess the effect of baroclinicity in periods of moderate wind and wave activity. In the run Pnoatm atmospheric forcing was not considered to enable understanding of the importance of this surface forcing. Several wave-current coupled runs were performed (PW) in order to assess the 2D and 3D coupling. Wave-current coupled runs considered the exchange of water depth and bottom and surface roughness. The PW2D run included the 2D Doppler shift while in the run PW2Dr both 2D Doppler shift and 2D radiation stress are considered. The PW3D incorporated the 3D Doppler shift, the PW3Ds included both 3D Doppler shift and Stokes drift while the PW3Dr included Doppler shift and 3D radiation stress.

The model hindcast is analysed and compared with observation within the estuary area. The statistical parameters used to quantify errors are:

$$
\mathrm{P}-\text { Bias }=100 \frac{\sum_{n=1}^{N}\left(M_{n}-O_{n}\right)}{\sum_{n=1}^{N}\left|O_{n}\right|}
$$




$$
\begin{gathered}
R M S E=\left[<(M-O)^{2}>\right]^{1 / 2} \\
D=1-\left[\sum_{n=1}^{N}\left(M_{n}-O_{n}\right)^{2} / \sum_{n=1}^{N}\left(\left|M_{n}-<O>\right|+\left|O_{n}-<O>\right|\right)^{2}\right]
\end{gathered}
$$

and the correlation coefficient, $r^{2}$. Where $<>$ denotes the mean values, $P$-Bias is the under or over prediction (in \%) of the model prediction $(M)$ compared with the observation $(O)$ and $R M S E$ is the root-mean-square error of the predicted model hindcast. The index of agreement $(D)$ is another quantity that measures the skill of the model to reproduce the observations and is bounded between 0 and 1, with 1 being the optimum model.

\section{Available Data}

The modelled and observed data used in the present work came from three locations in our study area (Figure 1). The WaveNet buoy managed by the Centre for Environment, Fisheries and Aquaculture Science (CEFAS, http://www.cefas.co.uk/data/wavenet.aspx) provides offshore wave parameters. The Welsh and Hilbre wave data are from moored instrument deployments during a set of Dee surveys performed in February-March 2008 (Bolaños and Souza, 2010). In the Hilbre channel an instrumented tripod with an upward looking ADCP (Acoustic Doppler Current Profiler) provides current velocity profiles with a vertical bin resolution of $0.5 \mathrm{~m}$ and integrated wave parameters. A second smaller rig was deployed in the Welsh channel providing near-bed current (from Acoustic Doppler Velocimeter, ADV) and pressure measurements. Estimates of wave parameters, using the PUV (Pressure, $u$ current component and $v$ current component) method (Gordon and Lohrmann, 2001) were performed. Note that no ADCP and, thus no current profiles, were available in the Welsh channel. A meteorological station located on the Hilbre Island complex provided hourly wind speed and direction. The prevailing 
conditions from the 25 February 2008 to the 07 March 2008 are considered to be a period of significant wave-influence (Figure 2), which is therefore the focus of this study.

\subsection{Environmental conditions}

Figure 2 shows the time series of hydrodynamic parameters during the studied period. Current speed (Figure 2a) and water depth (Figure $2 \mathrm{~b}$ ) are controlled by tides, following the spring/neap and flood/ebb cycles, velocities are slightly faster during floods and currents behave as in a standing wave with maximums occurring between high and low tide. The significant wave height $\left(H_{s}\right.$, Figure 2c) for the three locations shows the main wave event occurred on the 1 March 2008. Offshore, at the WaveNet position, large waves (about $5 \mathrm{~m} H_{s}$ ) result in direct response to the local wind forcing (Figure 3a) and show no tidal modulation. However, nearshore within the estuary channels, the wave height is reduced due to bathymetric features and modulated by the tide. Larger waves are evident at the Welsh channel mooring, the Hilbre channel mooring being less exposed to wave activity.

In the Hilbre channel the main current direction is aligned with N-S while the Welsh channel is E-W. In the Hilbre channel wave direction was predominantly from the $\mathrm{N}$, in agreement with the channel orientation. Mean periods in the area ranged from 3-6 seconds and peak periods from 4

- 10 seconds. River outflow was relatively small $\left(\sim 35 \mathrm{~m}^{3} \mathrm{~s}^{-1}\right)$ and constant during the study period peaking at $45 \mathrm{~m}^{3} \mathrm{~s}^{-1}$ on the 2 March.

The storm surge (Figure 2d) was obtained by applying tidal analysis to remove the tide. The Titan package (part of the Task-2000 package, http://www.pol.ac.uk/ntslf/software.html) with 16 
major and 15 related constituents was applied to the full record of sea surface elevation to obtain the residual elevation due to non-tidal effects (e.g. wave and meteorological setup and set-down). The plot shows that the storm surge peaked at nearly $0.8 \mathrm{~m}$ during the storm event, while a setdown was also observed during the calm period after the storm, reaching about $-0.8 \mathrm{~m}$. The surge during this study at the mooring locations has previously been validated (Brown et al., 2012; Brown et al., 2013a). The dominant component of the estuarine surge was found to be the surge generated externally to Liverpool Bay, while, the local meteorology and stratification were of secondary importance.

Figure 3 shows the time series of the wind speed and direction at Hilbre Island (a few hundred meters from the Hilbre channel deployment). The figure represents a two-month validation period of the mesoscale model under a wide range of conditions. It shows a few minor wind events with velocities of about $10 \mathrm{~m} \mathrm{~s}^{-1}$ and more intense wind events reaching up to $25 \mathrm{~m} \mathrm{~s}^{-1}$. A major wind event within the study period is observed to start on the 29 February 2008 with a maximum speed of $20 \mathrm{~m} \mathrm{~s}^{-1}$, duration of about 4 days and $\mathrm{SW}$ wind direction. During the 1 March 2008 the wind veered to the NW for about 12 hours producing the peak in significant wave height. The mesoscale (Met. Office) atmospheric model statistics are $\left(r^{2}=0.67, P\right.$-bias $=-$ 11.76 and $D=0.89)$ for wind speed and $\left(r^{2}=0.55, P\right.$-bias $=1.81$ and $\left.D=0.87\right)$ for wind direction.

\subsection{Wave processes within the estuary}

Waves inside the estuary are modulated by the tides (Figure 2c). During low tide the waves are restricted because most of the energy is dissipated on the sand banks extending out from the estuary mouth, only small waves or waves locally generated by the wind are able to occur in the channels. Figure 4 shows the relation of $H_{s}$ (left column) and $T_{z}$ (right column) with surface 
elevation for both the Hilbre (top panels) and Welsh (bottom panels) channels. Surface elevation is the main factor that controls wave propagation into the estuary, especially in the Hilbre channel where, during low water, the $H_{s}$ and $T_{z}$ are clearly reduced. The Welsh channel location is more exposed, with less influence from surrounding sandbanks and thus the tidal elevation has less influence on the waves. Some clustering can also be observed in the plots due to the flood and ebb currents, this effect is stronger for the wave periods due to a Doppler shift of the waves (decrease in $T_{z}$, during flood currents).

Waves can contribute to the overall storm surge through wave setup induced by the radiation stress (Brown et al., 2013b; Brown and Wolf, 2009; Longuet-Higgins and Stewart, 1964). The total (wave plus meteorological) surge peak (Figure 2c) correlates with the storm event, however, the separation of the meteorological induced and wave induced setup is not possible from these observations and thus only the total is shown. It is important to note that the peak of the surge occurs before the peak of $H_{s}$. This is because the surge interacts with the tide over the continental shelf. In Liverpool Bay the surge is mainly controlled by the external surge produced by the SW winds (see Jones and Davies, 1998), when the wind veers to the NW the external surge is reduced but local surge and $H_{s}$ in Liverpool bay is increased. The short fetches within the Dee for SW winds prevent counteraction of the external forcing at the estuary mouth. The surge has a strong correlation with the wind $\left(r^{2}=0.6\right.$ for the study period and $r^{2}=0.76$ for the main wave event) and less correlation with the local wave properties $\left(r^{2}<0.4\right.$ with $\left.H_{s}\right)$. The effect of waves on surge was explored further using model simulation, their effect was found to be marginal and isolated to the storm event during the 1 March 2008, when the winds were from NW inducing the largest waves approaching the estuary. 


\section{Results and discussion}

\subsection{Currents and wave-induced currents}

A comparison of the modelled depth-average velocity with observation in the Hilbre channel only (as no current profiles were available for the Welsh location) is presented in Figure 5. Model and data has been rotated along the main current axis independently to minimize possible errors due to bathymetry, position of the rigs and channel orientation. The model reproduces the velocities very well, especially the principal component which is aligned with the channel orientation. The minor-axis component is overestimated and some disagreements occur during the wind-wave event. The overall statistics $\left(P\right.$-Bias, $D$ and $\left.r^{2}\right)$ for the model runs in terms of depth-averaged velocity are presented in Table 2 . The main current component is clearly tidally dominated and thus error statistics are similar among the different runs, all of them showing very strong tidal signal. The main component is not very sensitive to the different wave processes included in the simulations. However, the minor-axis component of the depth-averaged velocity is sensitive to the wave processes. The largest errors in the minor-axis component occur when no wave effects are considered (P-ref) and the simplest inclusion of waves (PW2D) gives an improvement of the P-bias and RMSE. In general, the model produces very low correlation with the observation for this component, which could be attributed to an error in the model resolution at the location and/or model bathymetry, or inaccuracies in the baroclinic forcing. The minoraxis component in the Hilbre channel is less influenced by tidal forcing and circulation induced by atmospheric forcing, potentially enabling waves and lateral density gradients to have a 
stronger impact. The consideration of 3D radiation stress (PW3Dr) produced better results (lower P-bias and RMSE) than the other runs (see Table 2).

A snapshot of depth-averaged currents during the peak of the storm (1 March 2008) for the reference run (P-ref) and the runs including radiation stress (PW2Dr and PW3Dr) are shown in Figure 6. The outer part of the Welsh channel experiences large velocities and variable current direction due to the shape of the coastline, the curvature of the tidal channel and the bathymetry of the sand bank at the north of the channel. The consideration of radiation stress slightly modifies the pattern of the depth-averaged velocity. The $2 \mathrm{D}$ radiation stress produces a small reduction of the flow in the Welsh channel and induces some heterogeneity of the flow in the more offshore areas. The 3D radiation stress on the other hand produces an intensification of the flow in the Welsh channel. These differences, although small, have some relevance when looking into the details of the current profile and the residual circulation as shown next.

The long-term residual circulation is defined in the present work as the time-averaged velocity during the study period. In Figure 7 the observed and modelled residual circulation profiles in the Hilbre channel are presented. The observed major-axis component is aligned with channel orientation and displays a two-layer system with a surface layer flowing out of the estuary. The observed minor-axis component is vertically more uniform, flowing towards the central part of the channel. In agreement with Bolaños et al. (2013) for a calm period, the residual circulation profile (Figure 7) in the Hilbre channel is mainly controlled by the presence of density driven flow, thus, when not taken it into account the model produced less accurate patterns (Pnostrat) in both components. When baroclinic effects are considered the vertical profiles are well modelled 
(P-ref), although a weak two-layer structure does occur in the minor-axis current component. Wave processes are of lesser importance than stratification, but their inclusion improves the vertical profile of the modelled horizontal residual circulation (PW2D, PW2Dr and PW3Dr). The clearest improvement is by the 3D radiation stress in the main current component (PW3Dr). The radiation stress as proposed by Mellor (2003, 2005), which was also implemented in ROMS (Haas and Warner, 2009; Warner et al., 2008), showed improvement of the results when modelling the residual circulation profile within this estuary. However POLCOMS-WAM has previously been tested in Liverpool Bay (not shown) suggesting incorrect wave-setup during extreme storms due to unrealistic currents offshore (Brown at al., 2011). This is in agreement with discussions on the inconsistences of Mellor's derivation (Ardhuin et al., 2008a; Bennis et al., 2011), which have also led to alternative formulations (e.g. Vortex force, Lane et al., 2007; McWilliams et al., 2004) that have now been incorporated in the COAWST system based in the ROMS model (Uchiyama et al., 2010; Kumar et al., 2012).

Consideration of 3D radiation stress modifies the near-bed profile to a much greater extent than the other wave couplings. The improvements are due to an integrated effect of radiation stress over the area modifying the horizontal current profile in the mouth of the estuary, which in turn influences the flow within the estuary. In this case, the radiation stress generates a landward flow in the major-axis residual component over the entire depth, but with slightly greater flow velocity near the bed. This causes a shift in the overall velocity profile towards negative (landward) values improving the validity of this simulation, and thus, demonstrates the need to correctly represent the vertical profile of radiation stress to obtain an accurate residual current structure under wave conditions. Interestingly, the 2D radiation stress also improved the vertical 
profile of the major-axis residual current component, indicating that even though the process is formulated in 2D, when included in a 3D hydrodynamic model it induces improvements in the vertical structure. However, the two-layer structure in the minor-axis residual current is incorrectly enhanced as the model responds to the depth-uniform stress. These results also indicate that the wind-wave mixing during the storm event is not strong enough to overcome the effect of the baroclinic circulation, which is the primary driver of the circulation in the Hilbre channel. The SW winds during this event support wind strained stratification (as described by e.g. Chen and Sanford (2009) and Scully et al. (2005)), a down-estuary wind enhances subtidal vertical shear, which strains the along-channel density gradient to increase stratification; upestuary wind reduces or even reverses the vertical shear, thus tending to decrease stratification). Weakening of the stratification happens only near the peak of the storm. This is the why the two-layer system remains evident over the majority of the study period (eg. Brown et al., 2014). Stokes drift did not produce any significant change to the patterns simulated with the PW3D run (so PW3Ds is therefore not shown).

\subsection{Wave and surge modelling}

Waves are an important mechanism for triggering sediment re-suspension through the increase of bottom stress and generation of currents, thus it is important to model their properties accurately within the estuary. Figure 8 (first and second row) shows a comparison of modelled and observed significant wave height, $H_{s}$, and mean period, $T_{z}$, at the offshore (WaveNet) location. The major wave event between the 29 February 2008 and 5 March 2008 generates a significant wave height of more than $4.5 \mathrm{~m}$ and mean period of $7 \mathrm{~s}$. All wave model runs show similar patterns in terms of $H_{s}$ but an improvement is achieved by considering the 3D Doppler shift 
(PW3D) especially during the main peak of the storm. This improvement is seen more clearly in $T_{z}$ as the model very closely matches the pattern observed. The model shows a reduction of $P$ Bias and RMSE (Table 3) for the 3D runs due to the Doppler shift effect while the inclusion of radiation stress and Stokes drift did not produce significant changes.

Figure 8 (third to sixth row) shows the comparison of wave parameters $\left(H_{s}\right.$ and $\left.T_{z}\right)$ within the estuary mouth in both the Hilbre and Welsh channels. At these inshore locations, in contrast to the offshore WaveNet location, it is evident that wave dissipation occurs and that the tidal modulation of wave parameters becomes stronger. The observed wave events with $H_{s}$ greater than $3 \mathrm{~m}$ offshore are attenuated within the estuary, although less so in the Welsh channel than the Hilbre channel. Nearshore, the model runs accurately predicted the tidal oscillation of wave parameters, but $H_{s}$ was underestimated more so than offshore. In contrast to the offshore results, the 3D wave-current interaction processes (PW3D) do not improve the simulation of $H_{s}$ and, generally, the 2D run (PW2D) gives better results in terms of $H_{s}$. A slight improvement in $T_{z}$ occurs when considering 3D Doppler shift at both locations in the estuary mouth, the tidal modulations are better captured and the magnitude is better predicted. Due to of the importance of water depth variation for waves, errors in the wave simulation are likely to be highly affected by bathymetric inconsistency modifying the wave propagation and bottom friction dissipation.

Table 3 summarizes the model statistics for the wave parameters at the 3 study locations. The differences are due to wave-induced changes in the circulation, which in turn influences the refraction and Doppler shift of the waves and the representation (2D or 3D) of the current structure. There is an improvement in the modelled $H_{s}$ when considering 3D effects in the 
offshore location, but reduced accuracy within the Dee. For $T_{z}$ an improvement is observed in the $3 \mathrm{D}$ runs at all 3 locations.

The significant wave height distribution around the Dee estuary during the day of the storm peak (1 March 2008) is shown in Figure 9 for the PW2D (top panels) and PW3D (bottom panels) runs at times of low (right column) and high (left column) water. The influence of bathymetry is clearly seen to be stronger on the wave field when considering the 3D Doppler shift. At high water the structure of the main channels can clearly be seen in the maps of wave height and at low water the varying coastal bathymetric profile can be seen. During the first 12 hours of this day the winds veered from SW to NW producing relatively large waves approaching the estuary mouth. Most of the wave energy is dissipated over the sand banks at the estuary entrance. However, during high tide, waves of more than $1 \mathrm{~m}$ can penetrate deeper into the estuary. The PW2D and PW3D runs present significant differences nearshore and within the estuary. The consideration of the 3D currents in WAM produced stronger dissipation as the waves propagate towards the coast. This is because the more intense currents near the surface have stronger effects on surface waves. This generates larger horizontal wave gradients and clearly restricted wave propagation within the tidal channels. The implementation of a $2 \mathrm{D}$ or $3 \mathrm{D}$ current within WAM also changed the drying areas during low tide, however, at such tidal stage the wave processes are minimal within the estuary (Brown et al., 2013b).

In general terms the use of the 3D Doppler shift improved the modelling of wave parameters both offshore and nearshore. The only exception was for $H_{s}$ in the estuary, this could be associated to errors in the bathymetry and thus in wave dissipation which becomes more evident 
when wave periods are modified by 3D Doppler shift. The large tidal amplitude and the associated water depth variations, make the consideration of tidal effects for wave modelling very important in shallow (estuarine) water.

The sea level residuals were obtained from tidal analysis (see section 4.1). Both channels present the same patterns, a setup in surge during the peak of the storms and a lesser set-down in surge during calm condition surrounding the main wave event. The model accurately reproduced (not shown here but in Brown et al. (2012), Brown et al. (2013b) and Brown et al. (2011)) the general trend of the observation, however it produced some overestimation of surge during the peaks in storm conditions. This could be related to errors in the external surge generated by offshore wind and pressure as the storm tracks over the Irish Sea.

The wave processes do not produce any significant change in the surge elevation due to wave setup and increased surface or bottom roughness. This result seems somewhat paradoxical to the knowledge of storm surge produced by waves. However, the wave processes at the mooring sites within the estuary are highly controlled by dissipation at the estuary mouth and thus wave setup within the estuary is expected to be small. As discussed by Jones and Davies (1998), for SW winds in the Irish Sea the observed surge in Liverpool bay is dominated by the "external" forcing. For the present conditions, this external forcing is the main source of surge in the Dee estuary as it influences the elevation at the mouth and therefore the flow into and out of the estuary. The local wave conditions produced under SW winds are small, so is not a significant factor influencing surge in the Dee estuary. 


\subsection{Wave effects on water column turbulence and salinity distribution}

Waves and atmospheric forcing may affect the salinity and turbulence distribution in the water column in several ways, including direct turbulence production and weakening or strengthening of the stratification. Figure 10 shows different model simulations (at the mooring location in the Hilbre channel) of the distribution of salinity (left column), current shear squared ( $M^{2}$, central column) defined as $\left(\frac{\partial u}{\partial z}\right)^{2}+\left(\frac{\partial v}{\partial z}\right)^{2}$, and the turbulent kinetic energy shear production (P, right column) defined as $-\rho\left(\left\langle u^{\prime} w^{\prime}\right\rangle\left(\frac{\partial u}{\partial z}\right)+\left\langle v^{\prime} w^{\prime}\right\rangle\left(\frac{\partial v}{\partial z}\right)\right), \quad$ for the first 100 hours in March when the storm occurred. Where $\rho$ is water density, $u, v, w$ are the velocity components and $z$ is the vertical coordinate. $\left\langle u^{\prime} w^{\prime}\right\rangle$ and $\left\langle v^{\prime} w^{\prime}\right\rangle$ are the Reynolds stresses. The salinity distribution from model runs changes values significantly depending on the process included. The reference run (P-ref) is the one that presents the largest values showing stratification at low water and a wellmixed water column during high water. When removing the atmospheric forcing the salinity drops but the stratification increases. This is due to the removal of the storm surge that brings offshore waters into the estuary as well as the reduction of surface mixing, which results in the strengthening of baroclinicity. The effect of radiation stress (PW3Dr) also reduces the overall salinity but to a lesser extent than no atmospheric forcing (Pnoatm), and it does not change the strength of stratification at the Hilbre channel.

The current shear $\left(M^{2}\right)$ for the reference run (P-ref) and 3D radiation stress (PW3Dr) are similar and do not show a clear response to the tidal cycle, with large values at different tidal stages. However, the run without atmospheric forcing (Pnoatm) does show a clear cyclic pattern. The lack of wind forcing allows the stratification to slightly strengthen, which in turn produces stronger shear near the surface. This effect is observed especially at low tide, when baroclinic 
effects are more important. Near the bottom the shear is mainly induced by the bottom boundary layer and magnitudes are similar for each run.

The TKE production $(P)$ is closely linked to the $M^{2}$, and shows very similar patterns between the reference run (P-ref) and the radiation stress run (PW3Dr). However, the run without atmospheric forcing (Pnoatm) presents, controversially, larger turbulence values of $P$, typically close to the surface associated with the shear induced by the stratification and in some cases high turbulence throughout the water column, associated to bottom friction and the stronger river influence during low tide.

Weakening of stratification occurs during the peak of the storm due to enhanced mixing. However, the residual currents display a two-layer structure suggesting density driven currents are still the dominant process in generating the residual circulation within the Hilbre channel even during a wave influenced period. The strong effect of the baroclinic circulation shows that wave mixing within the estuary is small and stratification is persistent. The fact that stratification was persistent during the storm event could be related to: the storm's occurrence during a neap tide when stratification is strongest; slight increase on river outflow, the generally southerly wind direction during the study period supporting wind strained stratification; and the most energetic waves being dissipated on the offshore sand banks.

\subsection{Bottom stress}

Wave effects in the estuary are very important in terms of bottom stress in agreement with the findings of Umgiesser et al. (2004) and Bolaños et al. (2005) inside coastal lagoons. Figure 11 
shows the spatial distribution of maximum current stress for the 1 March 2008 and wave stresses for high and low water conditions corresponding to the times shown in Figure 9 (bottom panel). Current only stresses are of the order of $1 \mathrm{~N} \mathrm{~m}^{-2}$ and occur in the main tidal channel However, during high water levels, waves produce stresses that are more than a factor of 2 greater than those of the currents and have much greater intensity offshore. Within the estuary, high wave stresses occur in shallow areas, where most of their energy is dissipated, and not in the tidal channels where water depth is greater. At lower water levels the wave stress is limited to the channels due to banks drying. Within the channels during all tidal states the wave stresses are comparable to the current stresses. Therefore waves are important, enhancing the bottom stress and intensifying suspension of sediments, which can then be transported by the tidal currents and thus affect the morphology. At low water, waves only have influence at the estuary mouth, but with increasing depth, wave stresses can be generated up to the head of the estuary. Using either $2 \mathrm{D}$ or $3 \mathrm{D}$ currents in the wave model runs to estimate the bottom stress has an impact inside the estuary. The $2 \mathrm{D}$ run allowed larger waves to penetrate further into the estuary, increasing the estimated bottom stress over the shallow banks.

\section{Concluding remarks}

Measurements within estuarine channels and model results have been used to understand the relevant wave-flow interactions within a hypertidal estuary. A 3D coupled circulation model has been implemented considering 2D and 3D wave effects in the Dee estuary and has been used to assess the wave-current interactions. The circulation is controlled by tides and baroclinicity, while wave parameters inside the estuary are dependent on depth variations inducing wave 
dissipation over the outer sand banks. The ocean model showed good agreement in depthaveraged velocity and 3D residual patterns. Earlier studies (Bolaños et al., 2013) validated the 3D structure in more detail, which is not repeated here.

Waves within the estuary are strongly modulated by tides. Significant wave height and period are controlled by offshore wave conditions and water depth variations. Wave periods are also affected by currents, through Doppler shift. Thus, for accurate modelling of wave parameters the coupling with the ocean model to account for time-varying water depth and currents is necessary. Both, 2D and 3D Doppler shift improved the wave modelling, but the use of the 3D Doppler shift outperformed results using the 2D method at both offshore and nearshore locations.

An improved prediction of the residual circulation profile during storm conditions in the nearshore tidal channels was produced when using 3D radiation stress. However, it is computationally expensive and its effect over the longer term is minimal, since its influence is limited to isolated large wave events. Using a 2D radiation stress method avoids the highly debatable vertical distribution of its contribution, and together with its much faster computational time makes it more suitable for operational or long-term applications. In addition, this approach has been shown to be more robust offshore (Brown et al., 2013b), while its effect within the estuary are shown here to improve model performance.

Wave induced currents within the estuary are of second order compared with the baroclinic currents, thus the main long-term hydrodynamic patterns can be modelled without wave effects. Water column stratification would intuitively be expected to become reduced under more 
turbulent storm conditions due to wind and wave mixing, causing stratification induced currents to weaken. However, it is shown that the effect of the mixing process on residuals is relatively small when considering the full period of wave influence in this study.

However, for bed processes, the presence of waves is of primary importance. Waves can significantly increase the bottom stress, particularly in shallow areas, which may have consequences for the re-suspension of sediments which are then transported by the concurrent tidal currents. Sporadic wave events could be an important factor in shaping the estuary mouth and to a lesser extent the inner estuary and should therefore be considered in morphological studies.

The results have shown that the inclusion of radiation stress improved the residual current simulation within the estuary. However, density gradients due to river input, even with a small flow, have proved to be critical for the correct simulation of residual circulation, as also shown for a calm period by Bolaños et al. (2013), even during wave dominant conditions. Thus, when modelling long-term suspended particulate matter 3D effects and density gradients should be included in order to accurately predict the net transport pathways, along with the sediment sources and sinks.

\section{Acknowledgments}

This research has been carried out as part of the FORMOST project (NERC grant NE/E015026/1), the Ocean 2025 program, the FIELD_AC project (EU FP7 program grant No. 242284) and the iCOASST project (NERC grant NE/J005444/1). The support of the European 
Union through FP7, contract 288710 - MERMAID, is gratefully acknowledged. Jane Williams

(NOC) is thanked for providing the operational surge model output and meteorological (wind and pressure) data, while Clare O'Neill is thanked for providing the offshore temperature and salinity fields to the Irish Sea and supplementing the meteorological forcing with air temperature, humidity, and cloud cover to enable full atmospheric forcing. Observations used for model validation were obtained from BODC, COBS and CEFAS. The authors thank the suggestions from three reviewers which significantly help to improve the manuscript.

\section{References}

Andrews, D.G., McIntyre, M.E., 1978a. An exact theory of nonlinear waves on a Lagrangian mean flow. Journal of Fluid Mechanics 89, 609-646.

Andrews, D.G., McIntyre, M.E., 1978b. On wave action and its relatives. Journal of Fluid Mechanics 89, 647-664.

Ardhuin, F., Jenkins, A.D., Belibassakis, K.A., 2008a. Comments on "The three dimensional current and surface wave equations". Journal of Physical Oceanography 38, 1340-1350.

Ardhuin, F., Marie, L., Rascle, N., Forget, P., Roland, A., 2009. Observation and estimation of lagrangian, Stokes, and eulerian currents induced by wind and waves at the sea surface. Journal of Physical Oceanography 39, 2820-2838.

Ardhuin, F., Rascle, N., Belibassakis, K.A., 2008b. Explicit wave-averaged primitive equations using a generalized Lagrangian mean. Ocean Modelling 20, 35-60.

Babanin, A.V., 2006. On a wave-induced turbulence and a wave-mixed upper ocean layer. Geophysical Research Letters 33.

Babanin, A.V., Ganopolski, A., Phillips, W.R.C., 2009. Wave-induced upper-ocean mixing in a climate model of intermediate complexity. Ocean Modelling 29, 189-197.

Babanin, A.V., Onorato, M., Qiao, F., 2012. Surface waves and wave-coupled effects in lower atmosphere and upper ocean. Journal of Geophysical Research 117 (C11), 1-10.

Bender, L.C., Wong, K.C., 1993. The effect of wave-current interaction on tidally forced estuarine circulation. Journal of Geophysical Research 98, 16521-16528.

Bennis, A.C., Ardhuin, F., Dumas, F., 2011. On the coupling of wave and three-dimensional circulation models: choice of theoretical framework, practical implementation and adiabatic tests. Ocean Modelling 40, 260-272.

Bolaños, R., Brown, J.M., Amoudry, L.O., Souza, A.J., 2013. Tidal, riverine and wind influences on the circulation of a macrotidal estuary. Journal of Physical Oceanography 43, 29-50.

Bolaños, R., Osuna, P., Wolf, J., Monabiu, J., Sanchez-Arcilla, A., 2011. Development of the POLCOMSWAM current-wave model. Ocean Modelling 36, 102-115. 
Bolaños, R., Riethmuller, R., Gayer, R., Amos, C.L., 2005. Sediment transport in a tidal lagoon subject to varying winds evaluated with a coupled current-wave model. Journal of Coastal Research 21, e11-e26.

Bolaños, R., Souza, A.J., 2010. Measuring hydrodynamics and sediment transport processes in the Dee Estuary. Earth, Syst. Sci. Data 2, 157-165.

Bolaños, R., Wolf, J., Brown, J., Osuna, P., Monbaliu, J., Sanchez-Arcilla, A., 2009. Comparison of wavecurrent interaction formulation using the POLCOMS-WAM wave-current model, Coastal Engineering. World Scientific Publishing, Hamburg, Germany., pp. 521-533.

Brown, J., Bolaños, R., Howarth, M.J., Souza, A.J., 2012. Extracting sea level residual in tidally dominated estuarine environments. Ocean Dynamics 62, 969-982.

Brown, J.M., 2010. A case study of combined wave and water levels under storm conditions using WAM and SWAN in a shallow water application. Ocean Modelling 35, 215-229.

Brown, J.M., Bolaños, R., Souza, A.J., 2013a. Controls of monthly estuarine residuals: Eulerian circulation and elevation. Ocean Dynamics In press.

Brown, J., Bolaños, R., Souza, A.J., 2014. Process contribution to the time-varying residual circulation in tidally doinated estuarine environments. Estuaries and Coasts. In press.

Brown, J.M., Bolaños, R., Wolf, J., 2013b. The depth-varying response of coastal circulation and water levels to $2 \mathrm{D}$ radiation stress when applied in a coupled wave-tide-surge modelling system during an extreme storm. Coastal Engineering 82, 102-113.

Brown, J.M., Bolaños, R., Wolf, J., 2011. Impact assessment of advanced coupling features in a tidesurge-wave model, POLCOMS-WAM, in a shallow water application. Journal of Marine Systems 87, 1324.

Brown, J.M., Souza, A.J., Wolf, J., 2010. An 11-year validation of wave-surge modelling in the Irish Sea, using a nested POLCOMS-WAM modelling system. Ocean Modelling 33, 118-128.

Brown, J.M., Wolf, J., 2009. Coupled wave and surge modelling for the eastern Irish Sea and implications for model wind-stress. Continental Shelf Research 29, 1329-1342.

Chen, S., Sanford, L.P., 2009. Axial wind effects on stratification and longitudinal salt transport in an idealized, partially mixed estuary. Journal of Physical Oceanography 39, 1905-1920.

Chen, S.S., Zhao, W., Donelan, M.A., Tolman, H.L., 2013. Directional wind-wave coupling to fully coupled atmosphere-wave-ocean models: results from CBLAST-Hurricane. Journal of Atmospheric Sciences 70, 3198-3215

Donelan, M.A., Curcic, M., Chen, S., Magnusson, A.K., 2012. Modeling waves and wind stress. Journal of Geophysical Research 117, 1-26.

Fan, Y., Lin, S.J., Held, I.M., Yu, Z., Tolman, H.L., 2012. Global ocean surface wave simulation using a coupled atmosphere-wave model. Journal of Climate 25, 6233-6252.

Gordon, L., Lohrmann, A., 2001. Near-shore Doppler currentmeter wave spectra., Ocean wave measurement and analysis, pp. 33-43.

Groeneweg, J., Battjes, J.A., 2003. Three dimensional wave effects on a steady current. Journal of Fluid Mechanics 478, 325-343.

Holt, J.T., James, I.D., 2001. An S coordinate density evolving model for the northwest European continental shelf. Model description and density structure. Journal of Geophysical Research 106, 1401514034.

Holt, J.T., Umlauf, L., 2008. Modelling the tidal mixing fronts on seasonal stratification of the Northwest European continental shelf. Continental Shelf Research 28, 887-903.

Hutchinson, S.M., 1994. Distribution of 137Cs in saltmarsh sediments in the Dee Estuary, NW England. Marine Pollution Bulletin 28, 262-265.

Hutchinson, S.M., Prandle, D., 1994. Siltation in the saltmarsh of the Dee Estuary derived from 137Cs analysis of shallow cores. Estuarine, Coastal and Shelf Science 38, 471-478. 
Haas, K.A., Warner, J.C., 2009. Comparing a quasi-3D to a full 3D nearshore circulation model: SHORECIRC and ROMS. Ocean Modelling 26, 91-103.

Janssen, P.A.E.M., 1989. Wave-induced stress and the drag of air flow over the sea waves. Journal of Physical Oceanography 19, 745-754.

Jenkins, A.D., 1987. Wind and wave induced currents in a rotating sea with depth-varying eddy viscosity. Journal of Physical Oceanography 17, 938-951.

Jones, J.E., Davies, A.M., 1998. Storm surge computations fo the irish Sea using a three-dimensional numerical model including wave-current interaction. Continental Shelf Research 18, 201-251.

Jorda, G., Bolaños, R., Espino, M., Sanchez-Arcilla, A., 2007. Assessment of the importance of the current-wave coupling in the shelf ocean forecast. Ocean Science 3, 345-362.

Kirby, J.T., Chen, T.M., 1989. Surface waves on vertically sheared flows: approximate dispersion relations. Journal of Geophysical Research 94, 1013-1027.

Kumar, N., Voulgaris, G., Warner, J.C., Olabarrieta, M., 2012. Implementation of the vortex force formalism in the coupled ocean-atmosphere-wave-sediment transport (COAWST) modeling system for inner shelf and surf zone applications. Ocean Modelling 47, 65-95.

Lane, E.M., Restrepo, J.M., McWilliams, J.C., 2007. Wave-current interaction: a comparison of radiationstress and vortex-force representation. Journal of Physical Oceanography 37, 1122-1141.

Lin, R.Q., Perrie, W., 2003. Wave-current interactions in an idealized tidal estuary. Journal of Geophysical Research 108.

Longuet-Higgins, M.S., Stewart, R.W., 1962. Radiation stress and mass transport in gravity waves with applications to surf 'beats'. Journal of Fluid Mechanics 13, 481-504.

Longuet-Higgins, M.S., Stewart, R.W., 1964. Radiation stress in water waves: a physical discussion with applications. Deep-Sea Research 11, 529-562.

Makin, V.K., Kudryavtsev, V.N., 1999. Coupled sea surface-atmosphere model 1. Wind over waves coupling. Journal of Geophysical Research 104, 7613-7623.

Makin, V.K., Kudryavtsev, V.N., 2002. Impact of dominant waves on sea drag. Boundary-layer Meteorology 103, 83-99.

Mastenbroek, C., Burgers, G., Janssen, P.A.E.M., 1993. The dynamical coupling of a wave model and a storm surge model through the atmospheric boundary layer. Journal of Physical Oceanography 23, 1857-1866.

McWilliams, J.C., Restrepo, J.M., Lane, E.M., 2004. An asymtotic theory for the interaction of waves and currents in coastal waters. Journal of Fluid Mechanics 511, 135-178.

Mellor, G., 2002. Oscillatory bottom boundary layers. Journal of Physical Oceanography 32, 3075-3088.

Mellor, G., 2003. The three-dimensional current and surface wave equations. Journal of Physical Oceanography 33, 1978-1989.

Mellor, G., 2005. Some consequences of the three-dimensional current and surface wave equations. Journal of Physical Oceanography 35, 2291-2298.

Mellor, G., 2008. The depth-dependent current and wave interaction equations: A revision. Journal of Physical Oceanography 38, 2587-2525-2596.

Michaud, H., Marsaleix, P., Leredde, Y., Estournel, C., Bourrin, F., Lyard, F., Mayet, C., Ardhuin, F., 2012. Three-dimensional modelling of wave-induced current from surf zone to the inner shelf. Ocean Science 8, 657-681.

Monbaliu, J., Padilla-Hernandez, R., Hargreaves, J.C., Carretero, J.C., Luo, W., Sclavo, M., Gunther, H., 2000. The spectral wave model, WAM, adapted for applications with high spatial resolution. Coastal Engineering 41, 41-62.

Osuna, P., Wolf, J., 2005. A numerical study of the effect of wave-current interaction processes in the hydrodynamics of the Irish Sea, International Conference on ocean Waves and Analysis. WAVES., Madrid, Spain. 
Piedracoba, S., Souto, C., Gilcoto, M., Pardo, P.C., 2005. Hydrography and dynamics of Ría de Ribadeo (NW Spain), a wave driven estuary. Estuarine, Coastal and Shelf Science 65, 726-738.

Pleskachevsky, A., Eppel, D.P., Kapitza, H., 2009. Interaction of waves, currents and tides, and waveenergy impact on the beach area of Sylt Island. Ocean Dynamics 59, 451-461.

Rascle, N., Ardhuin, F., 2009. Drift and mixing under the ocean surface revisited: Stratified conditions and model-data comparisons. Journal of Geophysical Research 114.

Rascle, N., Ardhuin, F., Terray, E.A., 2006. Drift and mixing under the ocean surface: a coherent onedimensional description with application to unstratified conditions. Journal of Geophysical Research 111.

Roland, A., Cucco, A., Ferrarin, C., Hsu, T., Liau, J., Ou, S., Umgiesser, G., Zanke, U., 2009. On the development and verification of a 2-D coupled wave-current model on unstructured meshes. Journal of Marine Systems Doi:10.1016?j.jmarsys.2009.01.026.

Scully, M.E., Friedrichs, C.T., Brubaker, J.M., 2005. Control of estuarine stratification and mixing by windinduced straining of the estuarine density field. Estuaries 28, 321-326.

Sheng, Y.P., Liu, T., 2011. Three-dimensional simulation of wave-induced circulation: Comparison of three radiation stress formulations. Journal of Geophysical Research 116, $C 05021$.

Tang, C.L., Perrie, W., Jenkins, A.D., DeTracey, B.M., Hu, Y., Toulany, B., Smith, P.C., 2007. Observation and modelling of surface currents on the Grand Banks: A study of the wave effects on surface currents. Journal of Geophysical Research 112, C10025.

Uchiyama, Y., McWilliams, J.C., Shchepetkin, A.F., 2010. Wave-current interaction in an oceanic circulation model with a vortex-force formalism: Aplication to the surf zone. Ocean Modelling 34, 16-35. Umgiesser, U., Sclavo, M., Carniel, S., Bergamasco, A., 2004. Exploring the bottom stress variability in the Venice Lagoon. Journal of Marine Systems 51, 161-178.

Umlauf, L., Burchard, H., Bolding, K., 2005. General Ocean Turbulence Model. Source code documentation, Tech. Rep. 63. Baltic Sea Research Institute, Warnemunde, Germany.

Warner, J.C., Sherwood, C.R., Signell, R.P., Harris, C.K., Arango, H.G., 2008. Development of a threedimensional, regional, coupled wave, current, and sediment-transport model. Computers and Geosciences 34, 1284-1306.

Weber, J.E.H., Brostrom, G., Saetra, O., 2006. Eulerian versus Lagrangian approaches to the waveinduced transport in the upper ocean. Journal of Physical Oceanography 31, 2106-2118.

Wolf, J., Brown, J.M., Bolaños, R., Hedges, T., 2011. Waves in coastal and estuarine waters, Treatise on Estuarine and Coastal Science. Elsevier.

Wolf, J., Wakelin, S.L., Holt, J.T., 2002. A coupled model of waves and currents in the Irish Sea, International Offshore and Polar Engineering Conference, Kitakyushu, Japan., pp. 108-114. 


\section{Figure Captions}

Figure 1. Location of the Dee estuary in Liverpool Bay showing the model domain bathymetry and the location of the measured data. The white diamonds show the mooring locations in the Welsh channel (west) and Hilbre channel (east). The white square shows the WaveNet buoy position.

Figure 2. Measured time series of a) depth-averaged velocity in the Hilbre channel (positive for ebbs and negative for floods), b) water depth in the Hilbre channel, c) significant wave height at the three study locations and d) surge in the Hilbre and Welsh channels.

Figure 3. Wind speed (top) and wind direction (bottom) from observations and model.

Figure 4. Scatter plot of significant wave height $\left(H_{s}\right)$ and mean period $\left(T_{z}\right)$ against surface elevation for the Hilbre and the Welsh channels.

Figure 5. Time series of the observed and modelled depth-averaged current components in the Hilbre channel.

Figure 6. Depth-averaged velocity distribution during the peak of the storm (1 March 2008) for P-ref (left), PW2Dr (centre) and PW3Dr (right), model runs are identified in Table 1.

Figure 7. Residual circulation profile from observed ADCP data (mounted on the Hilbre rig) and modelled under different forcing terms given in Table 1. 
Figure 8. Observed and modelled significant wave height and mean period at the, offshore, WaveNet location (first and second row). Significant wave height $\left(H_{s}\right)$ within the Hilbre and Welsh channels (third and fourth row). Mean period $\left(T_{z}\right)$ in the Hilbre and Welsh channels (fifth and sixth row).

Figure 9. Distribution of significant wave height during high tide (left) and low tide (right) for the POLCOMS-WAM run PWG2D (top) and PWG3D (bottom) on the 1 March 2008.

Figure 10. Hilbre channel mooring location, left eft column is the salinity distribution (in PSU), central column is the current shear $\left(M^{2}\right.$ in $\left.\mathrm{s}^{-2}\right)$ and right column is TKE production $(P$ in $\mathrm{Wm}^{-3}$ ) for model results of P-ref (top row), Pnoatm (central row) and PW3Dr (bottom row). $M^{2}$ and $P$ have the same colour scale.

Figure 11. Distribution of maximum current stresses modelled by P-ref for the 1 March 2008 (left), wave stresses during high tide (centre) and low tide (right) for the PWG3D run (see Figure 9, bottom panels). Colour bar units in $\mathrm{N} \mathrm{m}^{-2}$, note the different colour scale between the current and wave stresses. 


\section{Tables}

Table 1. Description of the model runs and physical processes included. All runs included tidal and Coriolis forcing. Wave-current coupling runs considered the exchange of time-varying properties: current, depth, bottom and surface roughness.

\begin{tabular}{|c|c|c|c|c|c|c|c|c|}
\hline $\begin{array}{c}\text { Run } \\
\text { name }\end{array}$ & $\begin{array}{l}\text { Atmospheric } \\
\text { forcing }\end{array}$ & River & $\begin{array}{l}\text { wave-current } \\
\text { coupling }\end{array}$ & $\begin{array}{c}\text { 2D } \\
\text { Doppler } \\
\text { shift }\end{array}$ & $\begin{array}{c}2 \mathrm{D} \\
\text { radiation } \\
\text { stress }\end{array}$ & $\begin{array}{c}\text { 3D } \\
\text { Doppler } \\
\text { shift }\end{array}$ & $\begin{array}{c}\text { 3D } \\
\text { Stokes } \\
\text { drift }\end{array}$ & $\begin{array}{c}\mathrm{D} \\
\text { Radiation } \\
\text { stress }\end{array}$ \\
\hline P-ref & $\mathrm{X}$ & $X$ & & & & & & \\
\hline Pnoatm & & & & & & & & \\
\hline Pnostrat & $\mathrm{X}$ & & & & & & & \\
\hline PW2D & $\mathrm{X}$ & $\mathrm{X}$ & $\mathrm{X}$ & $\mathrm{X}$ & & & & \\
\hline PW2Dr & $\mathrm{X}$ & $\mathrm{X}$ & $\mathrm{X}$ & $\mathrm{X}$ & $\mathrm{X}$ & & & \\
\hline PW3D & $\mathrm{X}$ & $\mathrm{X}$ & $\mathrm{X}$ & & & $\mathrm{X}$ & & \\
\hline PW3Ds & $\mathrm{X}$ & $\mathrm{X}$ & $\mathrm{x}$ & & & $\mathrm{X}$ & $\mathrm{X}$ & \\
\hline PW3Dr & $\mathrm{X}$ & $\mathrm{X}$ & $\mathrm{X}$ & & & $\mathrm{X}$ & & $\mathrm{X}$ \\
\hline
\end{tabular}

Table 2. Statistical parameters for the depth-averaged velocity components (minor-axis component, $u$, and major-axis component, $v$ ) for the different model runs investigated.

\begin{tabular}{ccccccc}
\hline & P-ref & PW2D & PW2Dr & PW3D & PW3Ds & PW3Dr \\
\cline { 2 - 7 } P Bias $u$ & -59 & -46 & -52 & -47 & -49 & -36 \\
P Bias $v$ & 6 & 5 & 4 & 4 & 4 & -0.2 \\
RMSE $u$ & 0.0413 & 0.0382 & 0.0393 & 0.0389 & 0.0391 & 0.0391 \\
RMSE $v$ & 0.1237 & 0.1237 & 0.1232 & 0.1247 & 0.1252 & 0.1223 \\
$r^{2} u$ & 0.036 & 0.048 & 0.032 & 0.032 & 0.028 & 0.04 \\
$r^{2} v$ & 0.908 & 0.902 & 0.904 & 0.9 & 0.898 & 0.887 \\
$D \quad u$ & 0.92 & 0.92 & 0.92 & 0.92 & 0.92 & 0.93 \\
$D \quad v$ & 0.96 & 0.96 & 0.96 & 0.96 & 0.96 & 0.96 \\
\hline
\end{tabular}


Table 3. Statistic parameters of model performance for wave parameters at the 3 locations.

\begin{tabular}{|c|c|c|c|c|c|c|}
\hline \multirow{9}{*}{$\begin{array}{l}\bar{v}_{0} \\
\vec{\pi} \\
\vec{z}\end{array}$} & & PW2D & PW2Dr & PW3D & PW3Ds & PW3Dr \\
\hline & $P$ Bias $H_{s}$ & -22.8 & -12.6 & -12.6 & -12.6 & -12.8 \\
\hline & $P$ Bias $T_{z}$ & -23.4 & -6.1 & -6.2 & -5.8 & -7.0 \\
\hline & RMSE $H_{S}$ & 0.446 & 0.317 & 0.317 & 0.317 & 0.315 \\
\hline & $R M S E T_{z}$ & 1.180 & 0.436 & 0.440 & 0.442 & 0.465 \\
\hline & $r^{2} H_{s}$ & 0.911 & 0.938 & 0.938 & 0.938 & 0.939 \\
\hline & $r^{2} T_{z}$ & 0.593 & 0.851 & 0.850 & 0.838 & 0.850 \\
\hline & $D H_{s}$ & 0.934 & 0.968 & 0.968 & 0.968 & 0.968 \\
\hline & $\begin{array}{ll}D & T_{z}\end{array}$ & 0.690 & 0.939 & 0.938 & 0.937 & 0.933 \\
\hline \multirow{8}{*}{ 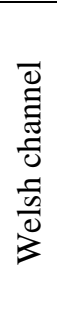 } & $P$ Bias $H_{s}$ & -15.5 & -30.7 & -30.8 & -30.8 & -31.2 \\
\hline & $P$ Bias $T_{z}$ & -11.9 & -7.8 & -7.6 & -7.7 & -7.5 \\
\hline & $R M S E H_{s}$ & 0.279 & 0.278 & 0.279 & 0.279 & 0.281 \\
\hline & $R M S E T_{z}$ & 0.921 & 0.603 & 0.602 & 0.02 & 0.591 \\
\hline & $r^{2} H_{s}$ & 0.721 & 0.867 & 0.868 & 0.868 & 0.869 \\
\hline & $r^{2} T_{z}$ & 0.250 & 0.508 & 0.504 & 0.505 & 0.539 \\
\hline & $D H_{s}$ & 0.902 & 0.892 & 0.890 & 0.890 & 0.887 \\
\hline & $\begin{array}{ll}D & T_{z}\end{array}$ & 0.628 & 0.792 & 0.791 & 0.791 & 0.804 \\
\hline \multirow{8}{*}{ 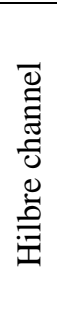 } & $P$ Bias $H_{s}$ & -30.5 & -54.1 & -54.4 & -54.4 & -55.0 \\
\hline & $P$ Bias $T_{z}$ & -9.5 & -9.7 & -9.1 & -9.2 & -9.4 \\
\hline & $R M S E H_{s}$ & 0.255 & 0.303 & 0.306 & 0.306 & 0.306 \\
\hline & $R M S E T_{z}$ & 1.183 & 0.716 & 0.710 & 0.709 & 0.680 \\
\hline & $r^{2} H_{s}$ & 0.692 & 0.829 & 0.837 & 0.838 & 0.852 \\
\hline & $r^{2} T_{z}$ & 0.0001 & 0.071 & 0.076 & 0.079 & 0.103 \\
\hline & $D H_{s}$ & 0.863 & 0.756 & 0.754 & 0.754 & 0.749 \\
\hline & $D \quad T_{z}$ & 0.335 & 0.527 & 0.537 & 0.539 & 0.558 \\
\hline
\end{tabular}




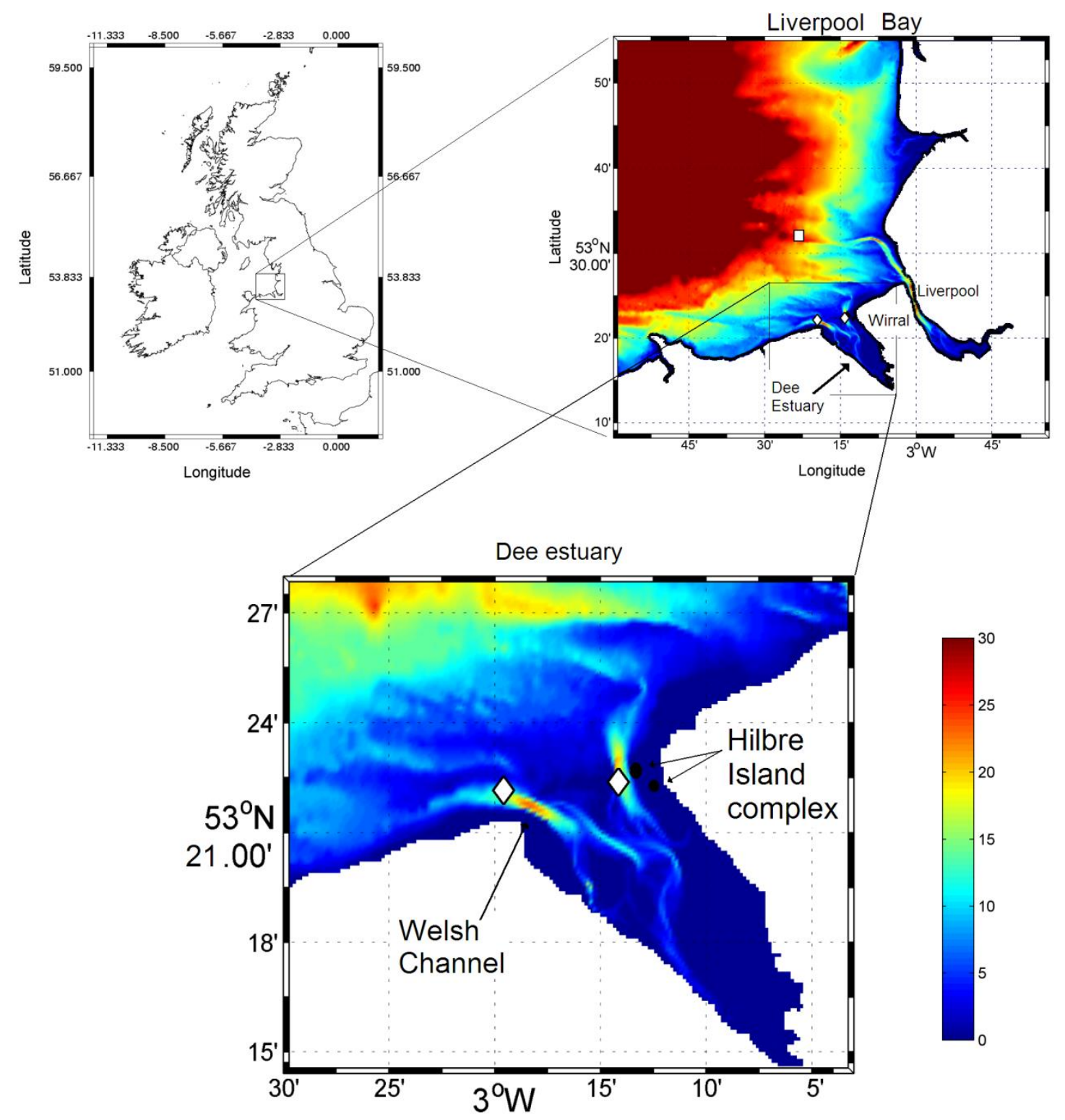

Figure 1. Location of the Dee estuary in Liverpool Bay showing the model domain bathymetry and the location of the measured data. The white diamonds show the mooring locations in the Welsh channel (west) and Hilbre channel (east). The white square shows the WaveNet buoy position. 

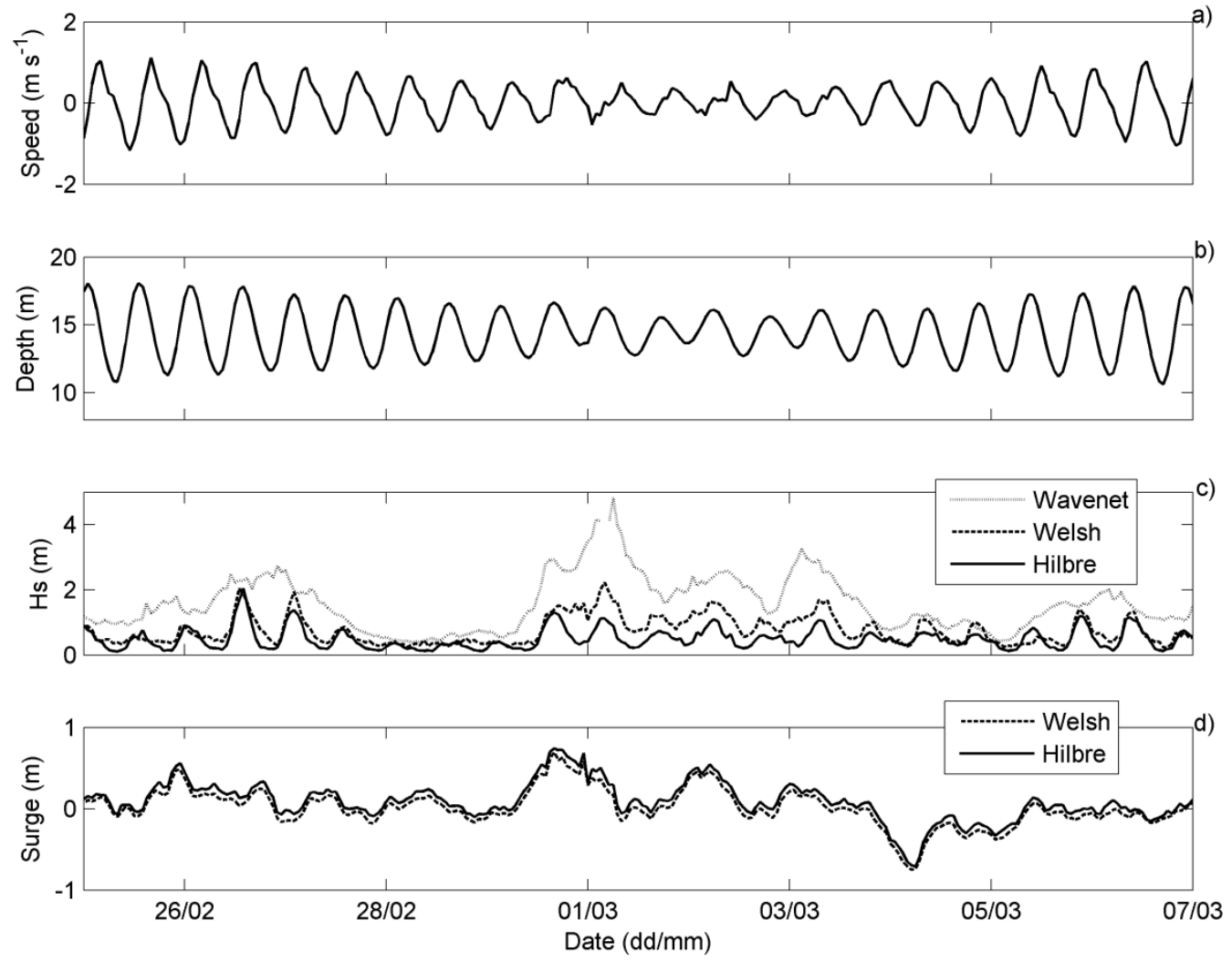

Figure 2. Measured time series of a) depth-averaged velocity in the Hilbre channel (positive for ebbs and negative for floods), b) water depth in the Hilbre channel, c) significant wave height at the three study locations and d) surge in the Hilbre and Welsh channels. 

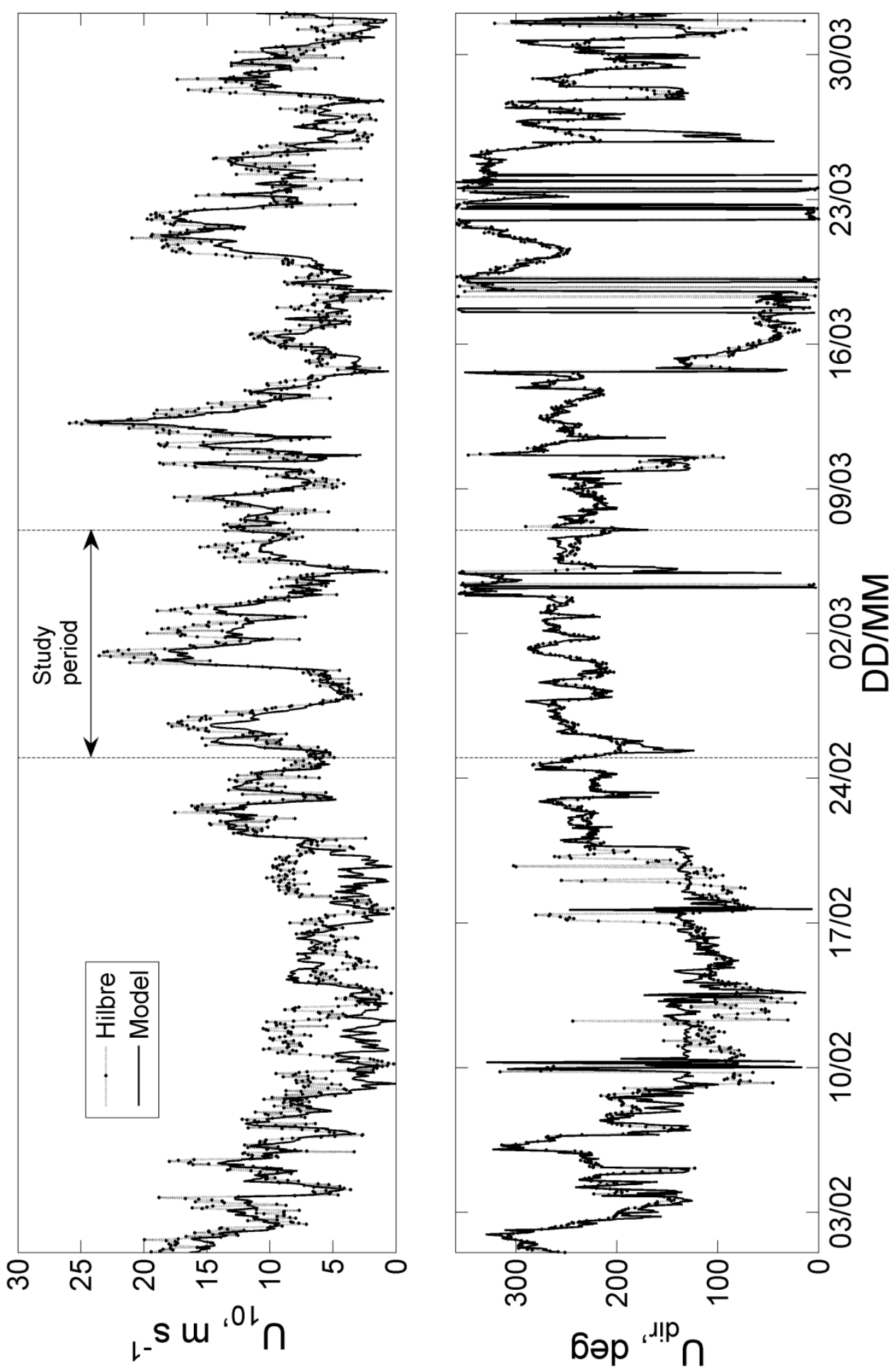

Figure 3. Wind speed (top) and wind direction (bottom) from observations and model. 

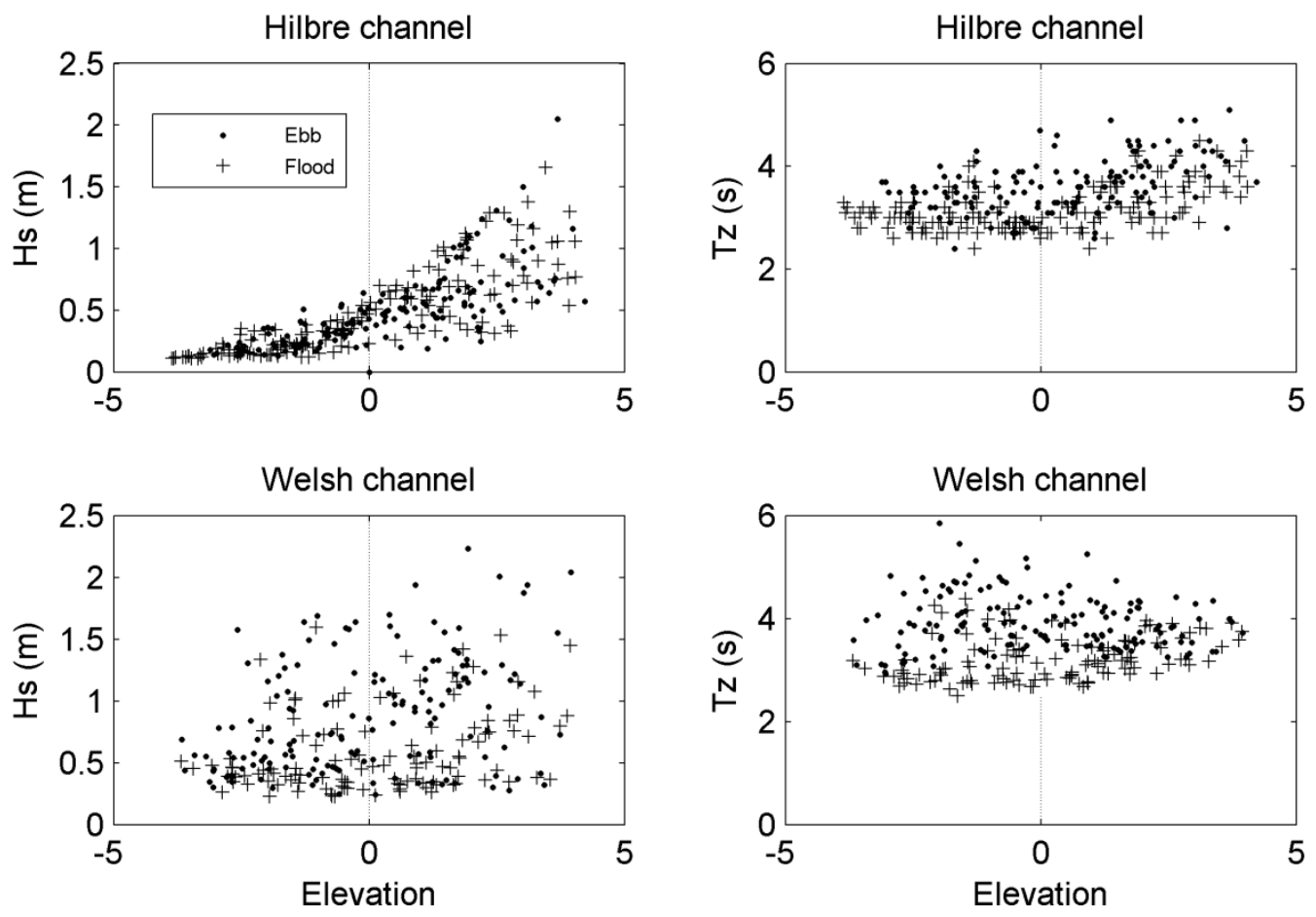

Figure 4. Scatter plot of significant wave height $\left(H_{s}\right)$ and mean period $\left(T_{z}\right)$ against surface elevation for the Hilbre and the Welsh channels. 

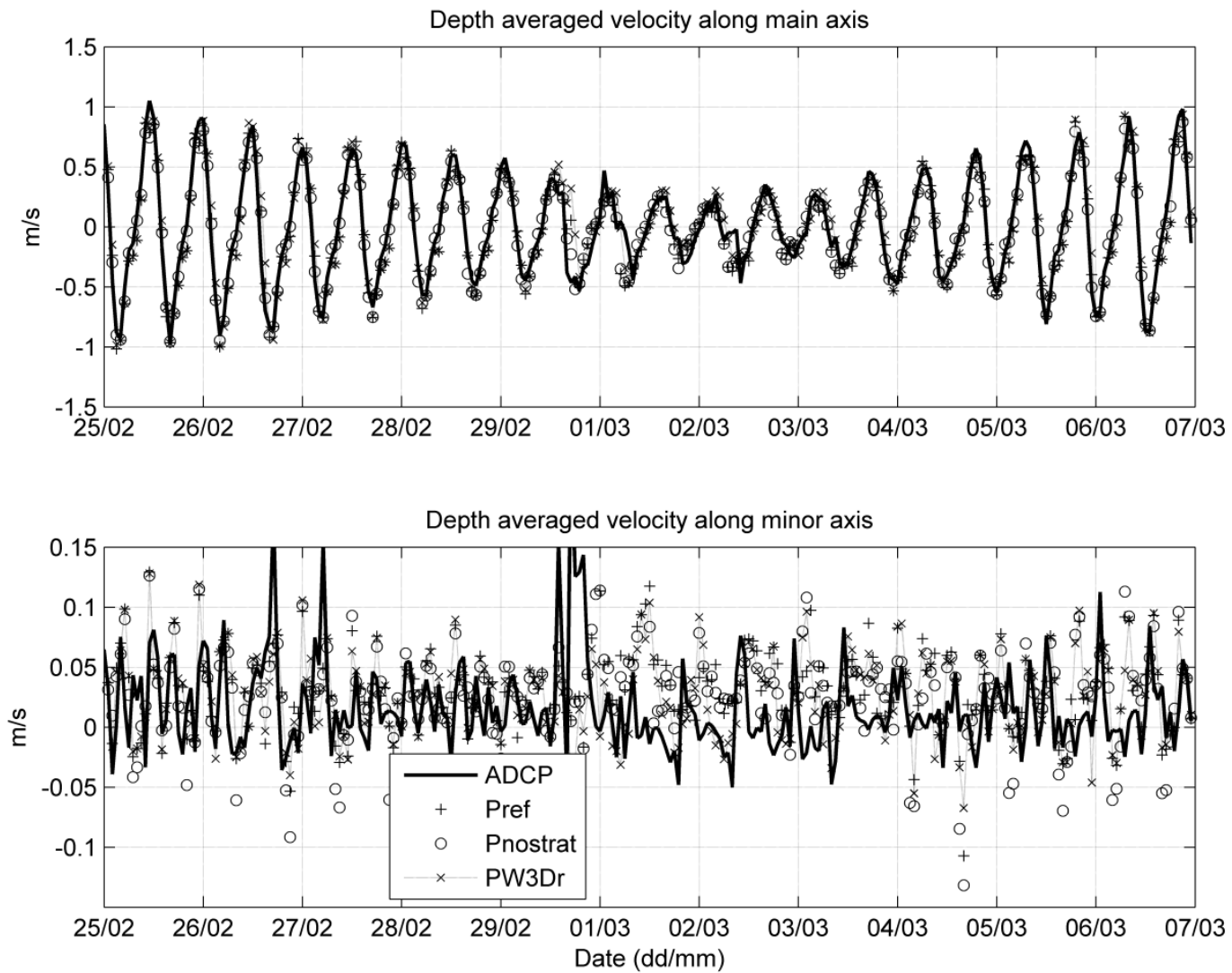

Figure 5. Time series of the observed and modelled depth-averaged current components in the Hilbre channel. 

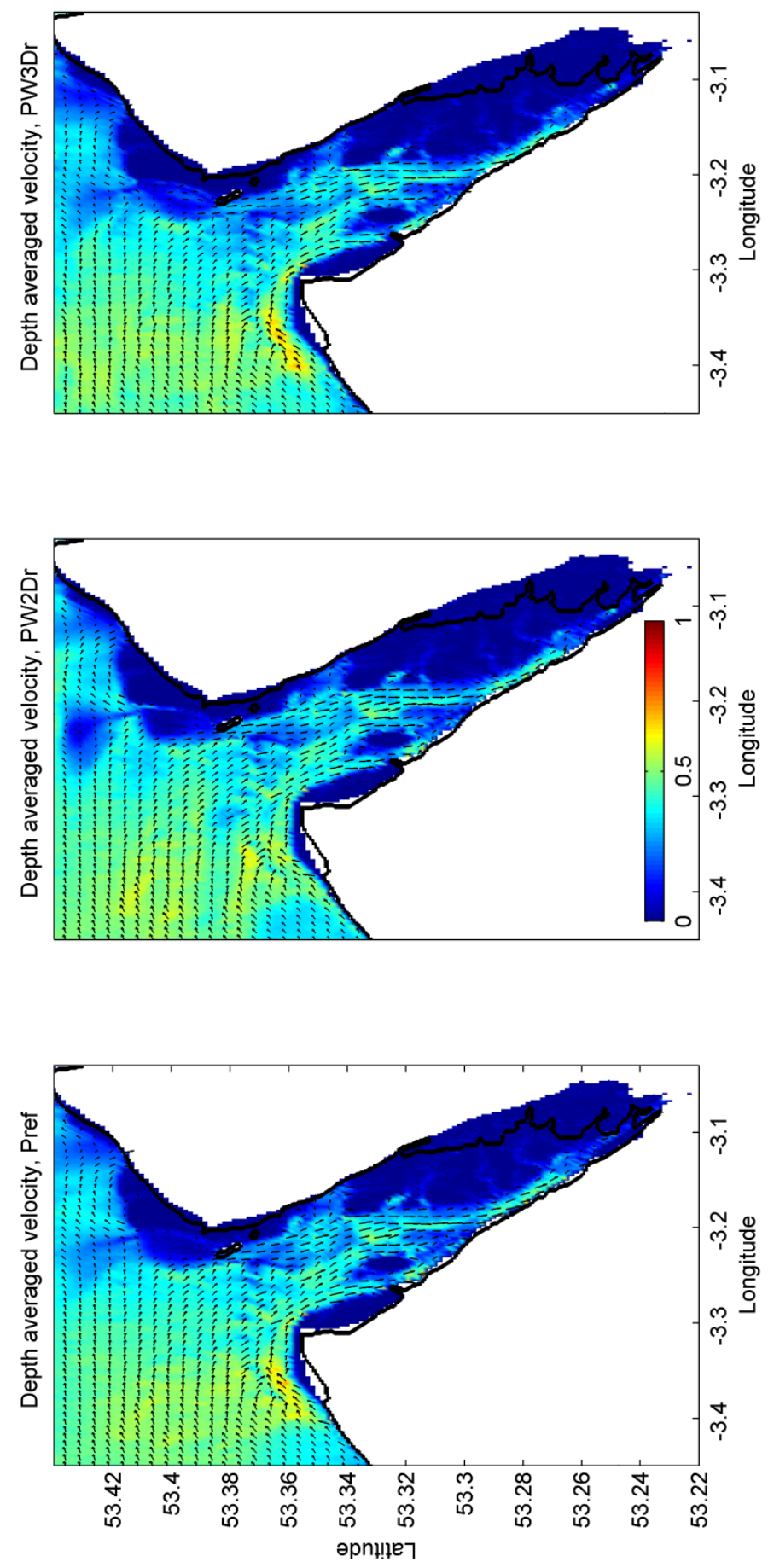

Figure 6. Depth-averaged velocity distribution during the peak of the storm (1 March 2008) for P-ref (left), PW2Dr (centre) and PW3Dr (right), model runs are identified in Table 1. 

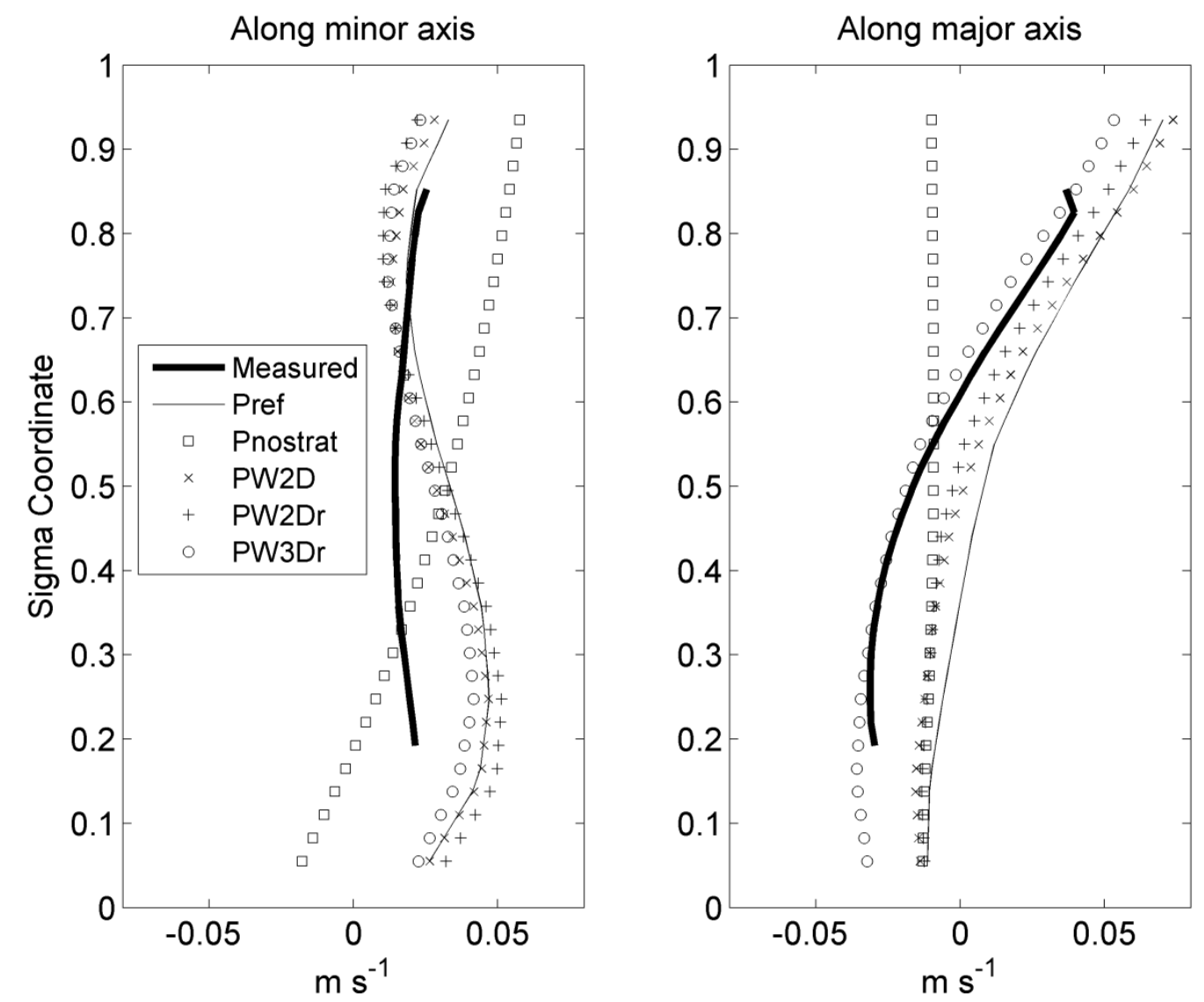

Figure 7. Residual circulation profile from observed ADCP data (mounted on the Hilbre rig) and modelled under different forcing terms given in Table 1. 

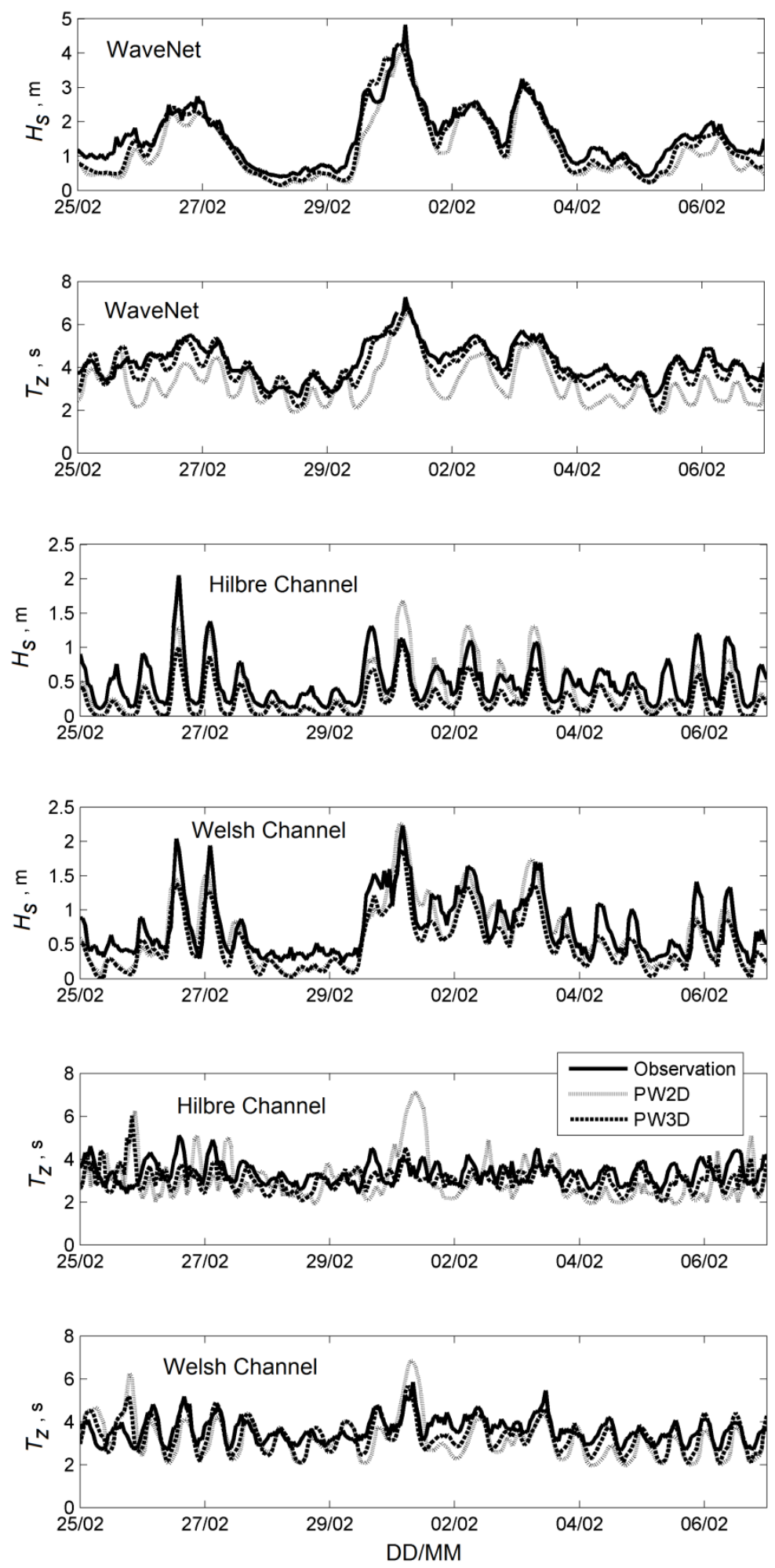

Figure 8. Observed and modelled significant wave height and mean period at the, offshore, WaveNet location (first and second row). Significant wave height $\left(H_{s}\right)$ within the Hilbre and Welsh channels (third and fourth row). Mean period $\left(T_{z}\right)$ in the Hilbre and Welsh channels (fifth and sixth row). 

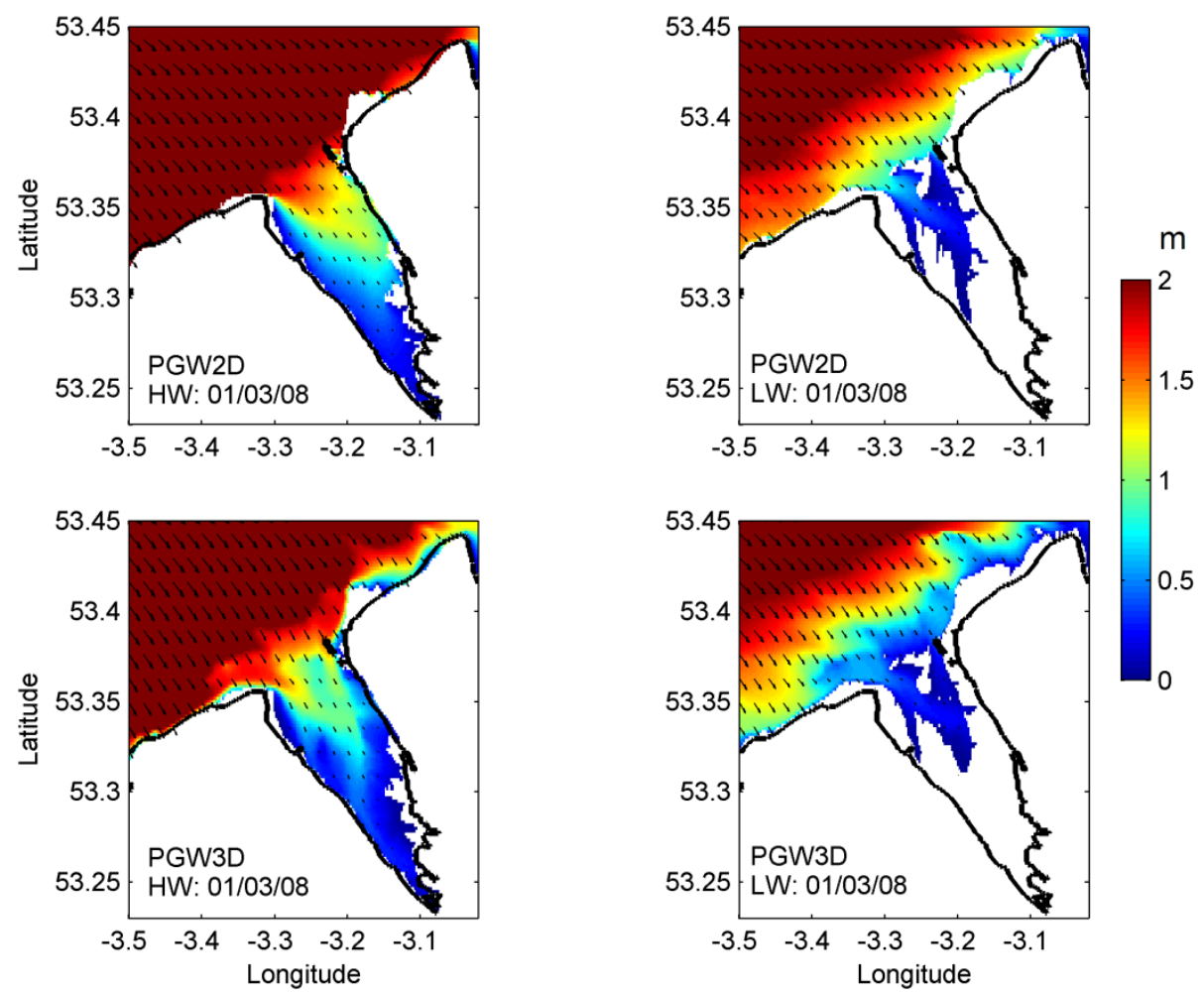

Figure 9. Distribution of significant wave height during high tide (left) and low tide (right) for the POLCOMS-WAM run PWG2D (top) and PWG3D (bottom) on the 1 March 2008. 

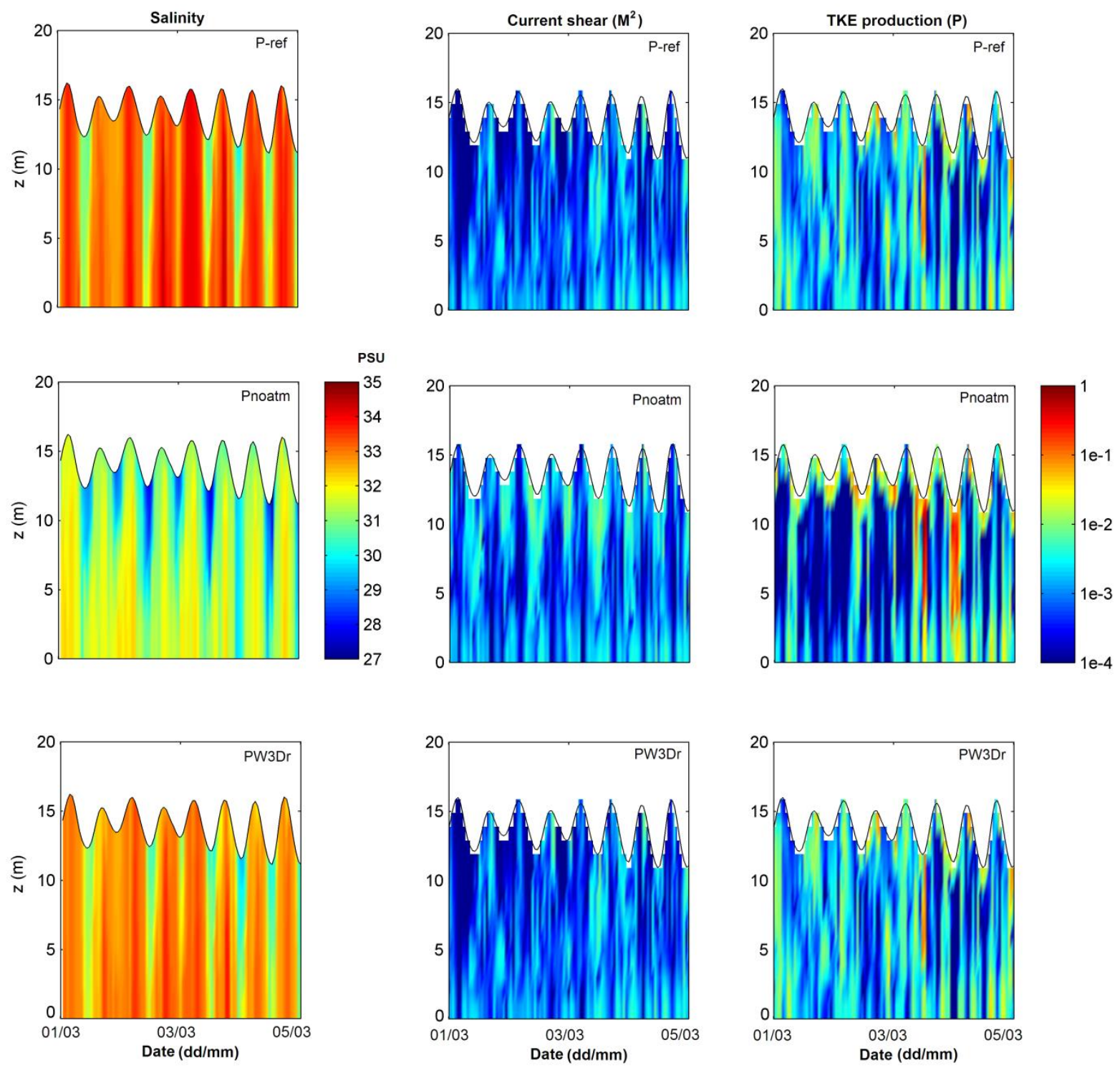

Figure 10. Hilbre channel mooring location, left column is the salinity distribution (in PSU), central column is the current shear $\left(M^{2}\right.$ in $\left.\mathrm{s}^{-2}\right)$ and right column is TKE production $(P$ in $\mathrm{Wm}^{-3}$ ) for model results of P-ref (top row), Pnoatm (central row) and PW3Dr (bottom row). $M^{2}$ and $P$ have the same colour scale. 

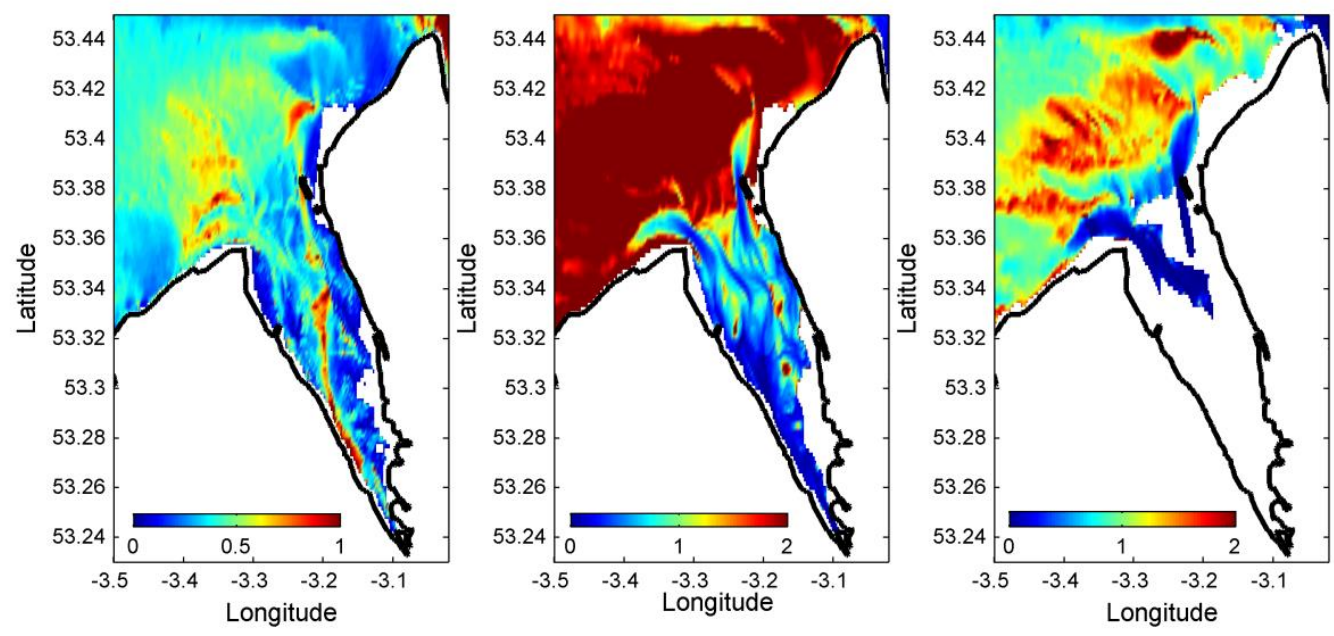

Figure 11. Distribution of maximum current stresses modelled by P-ref for the 1 March 2008 (left), wave stresses during high tide (centre) and low tide (right) for the PWG3D run (see Figure 9, bottom panels). Colour bar units in $\mathrm{N} \mathrm{m}^{-2}$, note the different colour scale between the current and wave stresses. 